\title{
Aspectos sustanciales y procesales \\ de la cooperación en la Red Europea \\ de autoridades de competencia ${ }^{*}$
}

Substantive and Procedural Issues of the Cooperation within the European

Competition Network

\author{
Aspectos substanciais e processais da cooperação na Rede Europeia \\ de autoridades de concorrência
}

Jesús Alfonso SOTO PinedA ${ }^{* *}$

FECHA DE RECEPCIÓN: 22 DE ABRIL DE 2014. FECHA DE ACEPTACIÓN: 16 DE ABRIL DE 2015

Doi: dx.doi.org/10.12804/esj 17.02.2015.05

Para citar este artículo: Soto Pineda, J.A., (2015). Aspectos sustanciales y procesales de la cooperación en la Red Europea de autoridades de competencia. Estudios Socio-Jurídicos, 17(2), 79-129. Doi: dx.doi.org/10.12804/esj17.02.2015.05

\section{RESUMEN}

Como resultado de la descentralización de la defensa de la competencia en la Unión Europea en el viejo continente se ha estructurado un foro de armonización y cooperación interinstitucional llamado Red Europea de Autoridades de Competencia, erigido para favorecer los enlaces entre las instituciones administrativas comunitarias y nacionales encargadas de proteger el mercado común. Dicho foro ha cumplido su tarea durante 10 años, gracias a un catálogo de instrumentos que fomentan los vínculos e impiden que se presenten asignaciones dobles de recursos entre autoridades. En ese sentido, el presente artículo expone los mencionados mecanismos de cooperación y coordinación, prestando especial atención a sus más relevantes características procesales y sustanciales y haciendo hincapié en los aciertos e inconvenientes que han presentado en su tiempo de vigencia así como en las modificaciones que adhiere a su ejecución la participación de la Comisión Europea, como eje central y preeminente de la defensa de la competencia comunitaria.

* El presente artículo de reflexión es resultado del trabajo de investigación realizado en el marco del proyecto titulado La defensa de la competencia, que adelanta el autor como miembro del Grupo de Investigación en Derecho y Economía del Departamento de Derecho Económico de la Universidad Externado de Colombia.

** Profesor investigador del Departamento de Derecho Económico de la Universidad Externado de Colombia. Doctor en Derecho y Ciencia Política por la Universidad Autónoma de Madrid. Magíster en Derecho Empresarial de la Universidad Autónoma de Madrid. Abogado de la Universidad Externado de Colombia, Bogotá, D.C., Colombia. Correo electrónico: jesus.soto@uexternado.edu.co 
Palabras clave: Defensa de la competencia, Red Europea de Autoridades de Competencia, cooperación vertical y horizontal, instrumentos de cooperación, instrumentos de coordinación.

\section{ABSTRACT}

As a result of the decentralization of the EC antitrust policy, a harmonization and inter-agency cooperation forum has been structured in Europe named European Competition Network, erected to promote the links between national and community administrative institutions responsible for protecting the competition in the common market. The above-mentioned forum has fulfilled its task for 10 years thanks to a catalog of instruments that in addition to promoting linkages, prevents that double and inappropriate allocations of resources arise. In that regard, this paper expounds the aforementioned cooperation and coordination mechanisms, taking special notice to their most relevant procedural and substantive features, highlighting the strengths and weaknesses that have arisen in its time of validity, and also the alterations that brings to its implementation the participation of the European Commission, as central and preeminent authority of the EC antitrust.

Key words: Antitrust, European Competition Network, Vertical and horizontal cooperation, cooperation mechanisms, coordination mechanisms.

\section{RESUMO}

Como resultado da descentralização da defensa da concorrência na União Europeia no velho continente se tem estruturado um fórum de harmonização e cooperação interinstitucional de autoridades de concorrência europeias que tem por nome Rede Europeia de Autoridades da Concorrência, erigido para favorecer os enlaces entre as instituições administrativas comunitárias e nacionais encarregadas de proteger o mercado comum. Este fórum tem cumprido sua tarefa durante 10 anos graças a um catálogo de instrumentos que fomentam os vínculos e impedem que se apresentem atribuições duplas de recursos entre autoridades. Nesse sentido, o presente artigo expõe os mencionados mecanismos de cooperação e coordenação, prestando especial atenção a suas mais relevantes características processais e substanciais, enfatizando nos acertos e inconvenientes que têm apresentado em seu tempo de vigência, assim como também nas modificações que a sua execução adere a participação da Comissão Europeia, como eixo central e preeminente da defensa da concorrência comunitária.

Palavras- chave: Defensa da concorrência, Rede europeia de autoridades da concorrência, cooperação vertical e horizontal, instrumentos de cooperação, instrumentos de coordenação. 


\section{Introducción}

Uno de los aspectos fundamentales del sistema de defensa de la competencia a nivel global es aquel referido a la cooperación entre autoridades nacionales de competencia de naturaleza administrativa. La dinámica globalizada de los mercados y la supranacionalidad de las relaciones comerciales imperantes en la actualidad han puesto de manifiesto una realidad en virtud de la cual una conducta restrictiva surgida en un emplazamiento particular, en pocas circunstancias restringe su impacto a aquel territorio, ya que suele trasladar su huella más allá de los mercados domésticos, al verse favorecida por la extensión actual del comercio.

De este modo, aquella condición intrínseca del ecosistema competitivo vigente se hace más profunda ahí donde los lazos de cercanía comercial son más estrechos, como sucede en la Unión Europea (en lo sucesivo UE). Por esta razón, en el sistema comunitario se ha entendido como prioridad estructurar un catálogo de instrumentos para favorecer la conjunción de actuaciones entre las múltiples autoridades empoderadas y, de esta manera, aplicar las normas de libre competencia comunitarias, ya que se ha entendido que actuando en bloque por medio de una Red europea de autoridades de competencia, se garantizan de mejor manera la disuasión y la efectividad del sistema de defensa de la competencia por completo. ${ }^{1}$

Tras once años en los cuales han sido puestos en marcha dichos instrumentos en procesos de libre competencia a lo largo y ancho de la Unión Europea, el presente artículo intenta exponer -aprovechando que el ejercicio de la actividad cooperativa no se ha visto modificado tras la aparición del Reglamento 1 del año 2003, la Comunicación de la Comisión sobre la

1 En la actualidad, la defensa de la competencia en Europa se desarrolla gracias a un sistema dual "público-privado" de aplicación de las normas de libre competencia. De acuerdo a dicho sistema, la aplicación pública de las normas de libre competencia comunitarias la llevan a cabo las autoridades administrativas de competencia (Comisión Europea en el nivel comunitario, y autoridades nacionales y territoriales de competencia en el nivel nacional de los Estados miembros de la Unión Europea) en busca de descubrir las conductas nocivas para la libertad de mercado y de tal forma estructurar correctivos y remedios idóneos para llevar dicha conducta al cese. Por otro lado, la aplicación privada de las normas de libre competencia está a cargo de los jueces y tribunales nacionales de los Estados miembros, en busca de definir los efectos civiles (daños y perjuicios) y el resarcimiento en favor de un particular al que da lugar una infracción a las normas de libre competencia comunitarias, toda vez que en virtud de un acto colusorio o de un abuso de posición de dominio, son susceptibles de generarse menoscabos a otros participantes del mercado o a los consumidores (Soto Pineda,2014). 
cooperación en la Red de autoridades de competencia y los instrumentos que le complementan ${ }^{2}$ - las principales características que han permitido transponer a la realidad, de forma continuada, la intención cooperativa europea en materia de libre competencia.

En ese sentido, el documento busca ordenar los instrumentos de armonización de facultades y de colaboración interinstitucional imperantes en la Unión Europea hasta nuestros días, respetando el carácter vertical u horizontal que incorporan, toda vez que, tal y como se verá, su ejercicio se ve modificado, en gran proporción, gracias a la participación o ausencia de la Comisión Europea (en lo sucesivo, también referida como, Comisión) en un asunto de libre competencia de naturaleza particular, ya que como máxima autoridad comunitaria de competencia, esta última ejerce una influencia especial en el derecho concurrencial de la Unión Europea.

Del mismo modo, el artículo presta especial atención a los aciertos que la reforma del año 2003 aparejó en lo referido a la compenetración entre Enforcement Bodies, ${ }^{3}$ a los inconvenientes que se han presentado en

2 La reforma que en el año 2003 surgió en la Unión Europea en materia de libre competencia es conocida en los ámbitos especializados como "el paquete de modernización de la defensa de la competencia", razón por la cual en el presente documento, al aludir al conjunto de instrumentos que la conformaron -y siguen conformándola en virtud de su vigencia-, cambiando la perspectiva que sobre la materia se tenía en los territorios europeos involucrados con la Unión, se hará referencia a "la reforma del año 2003". Los instrumentos jurídicos que forman parte de la mencionada reforma del año 2003 son, a saber, el Reglamento 1/2003, de 16 de Diciembre de 2002, relativo a la aplicación de las normas sobre competencia previstas en los artículos 81 y 82 del TCE, el Reglamento (CE) 773/2004 de la Comisión, de 7 de Abril de 2004, relativo al desarrollo de los procedimientos de la Comisión con arreglo a los artículos 81 y 82 del Tratado CE; así como por un compendio de Comunicaciones y directrices fechadas el día 27 de Abril de 2004, publicadas en el Diario Oficial de la Unión Europea C 101/05: la Comunicación de la Comisión sobre la cooperación en la Red de autoridades de competencia (p. 43), la Comunicación de la Comisión relativa a la cooperación entre la Comisión y los órganos jurisdiccionales de los Estados miembros de la Unión Europea para la aplicación de los artículos 81 y $82 C E$ (p. 54), la Comunicación de la Comisión relativa a las orientaciones informales sobre cuestiones nuevas relacionadas con los artículos 81 y 82 del Tratado CE que surjan en asuntos concretos (cartas de orientación) (p. 78), la Comunicación de la Comisión sobre la tramitación de denuncias por parte de la Comisión al amparo de los artículos 81 y 82 del Tratado CE (p. 65), las Directrices relativas al concepto de efecto sobre el comercio contenido en los artículos 81 y 82 del Tratado (p. 81) y las Directrices relativas a la aplicación del apartado 3 del artículo 81 del Tratado (p. 97).

3 El anglicismo Enforcement Bodies, del mismo modo que los vocablos propios de la lengua inglesa: Enforcement y Enforcers, se emplean en el presente documento toda vez que no existen expresiones en la lengua castellana que comporten una traducción precisa para ellos y que les confieran la amplitud conceptual adecuada que tienen dichas locuciones en su lengua original. De tal modo, al hablar de Enforcement Bodies o de Enforcers, se hace referencia a todos los cuerpos colegiados o individuales que tienen facultades de administración de justicia y/o aplicación de las normas -en este caso las normas de libre competencia-, a saber: la Comisión Europea, las autoridades nacionales de competencia, las autoridades autonómicas, regionales, municipales y locales de defensa de 
el tiempo de vigencia, los vacíos que a pesar de su importancia se han mantenido irresolubles, limitando el alcance de la intención supranacional, y los efectos e impacto que ha generado en la defensa de la competencia de la Unión Europea.

Por medio del presente artículo, además de poner a disposición del lector una referencia doctrinal que le acerque a los instrumentos de cooperación europeos, será posible inferir, tanto el alcance internacional que podrían tener estos últimos en iniciativas de la misma índole, como la trasposición verosímil a la cual podrían dar lugar en un sistema global de cooperación en materia de libre competencia.

\section{La cooperación y consolidación de la red europea de autoridades de competencia}

La descentralización del sistema de defensa de la competencia en la UE no significa en exclusiva otorgarle a las autoridades administrativas y a los Jueces de los Estados miembros facultades de aplicación de la normativa de libre competencia comunitaria, ${ }^{4}$ sino también -como demostración de aquella intención - instaurar un escenario verosímil en el cual el desenvolvimiento de todos los Enforcement Bodies involucrados con la aplicación de las normas de libre competencia comunitarias ${ }^{5}$ - gracias a la disposición de instrumentos cooperativos adecuados- sea fluido y eficaz.

la competencia en la Unión Europea, los jueces nacionales y los árbitros, condición sustentada en Brammer (2009, p. 1). Del mismo modo, al hacer referencia en el presente documento al "Enforcement", se alude -de forma unificada- a las múltiples etapas que dispone el sistema -en este caso la defensa de la competencia-, de forma organizada y sistemática, para (i) descubrir, (ii) disuadir, (iii) rehabilitar, y (iv) sancionar, las conductas y los actores que se aparten del cumplimiento de los parámetros normativos de la libre competencia.

4 Las normas fundamentales en las cuales se soporta el Derecho de la libre competencia de la Unión Europea son el artículo 101 del Tratado de Funcionamiento de la Unión Europea, en materia de acuerdos colusorios y prácticas concertadas; el artículo 102 del mismo instrumento, enunciado en materia de abuso de posición dominante; los artículos 106, 107, 108 y 109 en materia de ayudas públicas, y el Reglamento 139/2004 sobre control de concentraciones empresariales.

5 Cabe resaltar en este punto los instrumentos normativos de los cuales se nutre el Derecho comunitario. Así, el Derecho comunitario primario está compuesto por los Tratados de la Unión Europea, constitutivos y de funcionamiento, que equivalen a una constitución formal de la Unión, de obligatoria adopción en los países miembros, la cual se adhiere de forma automática a la legislación doméstica; y el Derecho comunitario derivado, que está constituido a su vez -en orden y de acuerdo al grado de obligatoriedad en su cumplimiento por parte de las diversas autoridades de los 
El apartado 15 del Reglamento $1 / 2003^{6}$ fue el encargado de introducir a la regulación comunitaria aquel propósito en lo referido a las autoridades administrativas de competencia. Por medio de aquel apartado, el legislador europeo expuso su intención de congeniar todos los poderes que le habían sido otorgados a las autoridades nacionales de competencia y a la Comisión Europea, en virtud de la descentralización de la libre competencia comunitaria. ${ }^{7}$ De ahí que propusiese crear un cuerpo "colegiado" de cooperación y trabajo conjunto, que favoreciese la nueva dinámica descentralizada de la libre competencia europea y garantizase la armonización de facultades, ${ }^{8}$

Estados miembros, al margen de sus diversas características de efecto y aplicación directa-, por las directivas, reglamentos, recomendaciones y decisiones (Borchardt, 2000, pp. 58-59).

6 Reglamento (CEE) No. 1/2003, del 16 de Diciembre de 2002, relativo a la aplicación de las normas sobre competencia previstas en los artículos 81 y 82 del TCE (Artículos 101 y 102 del Tratado de funcionamiento de la Unión Europea (en lo sucesivo TFUE).

7 En lo referido a la jerarquía institucional en materia de libre competencia en la Unión Europea, vale la pena reseñar que el sistema de defensa de la competencia a nivel comunitario está compuesto por tres tipos concretos de autoridad: la comunitaria, las nacionales y las territoriales. Así, como su nombre lo indica, las autoridades nacionales y las territoriales son aquellas que se encargan de proteger el marco de la libre competencia en un emplazamiento particular, interesándose, por tanto, en exclusiva, de las posibles distorsiones que se presenten en el mercado concreto que coincide con sus lindes. Por el contrario, la autoridad comunitaria -la Comisión Europea- se encarga de velar por dicho marco de libre competencia, a nivel supranacional, en todos los países miembros de la Unión Europea, circunstancia que le confiere un papel central en el ejercicio del sistema de libre competencia y le permite erigirse, en jerarquía, como la máxima autoridad de competencia comunitaria. Por lo tanto sus decisiones están por encima y en preeminencia de las decisiones o pronunciamientos de las autoridades nacionales de competencia o de las territoriales, toda vez que es la encargada de la formulación, implementación y orientación de la política de competencia en toda la Unión Europea con absoluta independencia y con atribuciones especiales de investigación y sanción. Los méritos de aquel protagonismo jerárquico de la Comisión Europea pueden encontrarse en: Unión Europea, Tribunal de Justicia de la Unión Europea. Sentencia C-234 de 1989, Stergios Delimitis Vs. Henninger Bräu AG, (28 feb., 1991). Disponible en http://eurlex.europa.eu/LexUriServ/ LexUriServ.do?uri=CELEX:61989J0234:EN:HTML. Unión Europea, Tribunal de Justicia de la Unión Europea. Sentencia T-24/90, Automec Srl Vs. La Comisión de las Comunidades Europeas, apartados 44, 47 y 73. (18 de sep. de 1992). Unión Europea, Tribunal de Justicia de la Unión Europea. Sentencia C-344/98, Apartado 47 y 73, (14 dic de 2000). Disponible en http://eurlex.europa.eu/LexUriServ/ LexUriServ.do?uri=CELEX:61998J0344:ES:PDF. Del mismo modo, resulta relevante el papel de la doctrina en la consolidación de aquel poder jerárquico (Dabbah, 2010, p. 169; Massey, 2002; Pace, 2007, p. 199).

8 En virtud del peligro que significa para el sistema de defensa de la competencia que las diversas autoridades empoderadas en la Unión Europea para aplicar las normas de referencia -independientemente de su alcance territorial- no actúen de forma coordinada y armonizada. Razón por la cual en la Unión Europea se determina que la Comisión Europea, como máxima autoridad de competencia comunitaria, se encuentra empoderada para hacerse cargo de todos aquellos casos en los cuales la dimensión de la conducta de relevancia para la defensa de la competencia, no sea solo doméstica, sino también supranacional, al tener la capacidad de generar efectos negativos en el tránsito comercial entre Estados miembros de la Unión Europea. Así, esta es competente para conocer de asuntos de libre competencia, de acuerdo al nivel de "dimensión" de la conducta. Además, tiene 

de competencia".

El Reglamento 1/2003 reforzó aquella premisa en su artículo $11,{ }^{10}$ y desarrolló los parámetros esenciales del marco general de cooperación entre las distintas autoridades públicas, en virtud del cual se le otorgó a la Red Europea de Autoridades de Competencia un papel central en la implementación de la descentralización, ${ }^{11}$ sirviendo de plataforma para la gestión, intercambio y consulta de información; y a su vez - no siendo menos importante- como escenario de discusión de asuntos, generales o particulares, relacionados con la defensa de la competencia. ${ }^{12}$

la capacidad de desplazar a las autoridades nacionales o territoriales de competencia de los Estados miembros en el conocimiento de un caso particular, dadas las características "macro" que agrupa y el impacto probable que puede conllevar, excediendo los límites territoriales (Tosato, 2006, p. 297).

9 Esta figura, como algunas otras de la defensa de la competencia en la UE, tiene un claro parangón en la Red que en los Estados Unidos conforman la Federal Trade Commission y las distintas autoridades Estatales. De la cual, si bien pueden extraerse similitudes con la Red Europea de Autoridades de Competencia, se deducen distintivos que le hacen más efectiva, toda vez que su estructura centralizada le permite evitar incongruencias que actualmente en la UE aún son susceptibles de presentarse con regularidad, y a su vez, incorpora en la discusión y el debate de asuntos de relevancia, a personas y organismos de diversa naturaleza jurídica, tales como Tribunales, Fiscales, abogados en ejercicio, etc., que, con la guía inequívoca de la principal Autoridad de competencia en Estados Unidos, ayudan a enriquecer el conocimiento acerca de una situación particular (Parada Vásquez, 2005, p. 154).

10 Así como en los apartados 16, 17, 18 y 32, que a los ojos de algunos no brindan un desarrollo suficiente y formal a tan importante e influyente figura en el marco de la defensa de la competencia, pues son solo parte de un débil y restringido desarrollo que hace carecer a la Red Europea de Autoridades de Competencia de una base legal formal que le soporte en el Reglamento 1/2003, como lo defiende, Van Der Woude (2003, p. 9), aunque centrado en la ausencia de lineamientos claros en el Reglamento 1/2003 acerca de cuáles son las autoridades de carácter público y nacional de los Estados miembros que conforman la Red, y los detalles que deben ser atendidos para que autoridades de magna diferencia, resultado de distintos sistemas de aplicación, no choquen continuamente entre sí (Idot, 2004, p. 211).

11 Acerca de la Red y la evolución que trajo al sistema de defensa de la competencia europeo, a pesar de su "formalización tibia" en el mismo Reglamento 1/2003, consultar: Dekeyser, K. \& Dalheimer, D., (2005 Cooperation within the European Competition Network - Taking stock after 10 months of case practice, en Lowe, Philip y Reynolds, Michael (edit.), Antitrust Reform in Europe: a year in practice, (pp. 105-123), Londres, International Bar Association, y Wils, W. (2004. The EU Network of Competition Authorities, The European Convention on Human Rights and the Charter of Fundamental Rights of the EU, en C.D. Ehlermann, \& I. Atanasiu (eds.), European Competition Law Annual 2002: Constructing the EU Network of Competition Authorities, (pp. 433-464), Oxford, Hart Publishing.

12 Tal y como se extrae de la lectura del artículo 14 del Reglamento $1 / 2003$, en el cual se desarrolla la figura del Comité Consultivo, como importante inclusión de la nueva realidad descentralizada. 
La Red Europea de Autoridades de Competencia, como marco idóneo para la cooperación y armonización de competencias entre Enforcers, es un foro exclusivo para oficiales y funcionarios de las autoridades de competencia, de naturaleza pública, que se extienden a lo largo y ancho de la UE. Esto significa que no forman parte de ella otros grupos de interés involucrados en la protección del ecosistema competitivo europeo, tales como abogados, académicos, empresarios y similares, ${ }^{13}$ situación que le diferencia de otro tipo de iniciativas, ${ }^{14}$ como la Asociación de autoridades de competencia europeas (ECA), ${ }^{15}$ en la cual los escenarios de discusión son informales, aunque con intereses similares a los de la Red, ${ }^{16}$ tales como incrementar la cooperación entre autoridades por medio de la celebración de reuniones, creación de grupos de trabajo e impulso al intercambio de información no confidencial, experiencia, o personal. ${ }^{17}$

A pesar de no existir una identidad "institucional" formalmente constituida en el Reglamento 1/2003 o en la Comunicación de la Comisión sobre la cooperación en la Red de autoridades de competencia (2004) (en lo sucesivo Comunicación sobre la Red) -toda vez que la creación del foro cooperativo no configura por sí misma la disposición de una organización definida ${ }^{18}$

13 Esto se concluye tras leer los pocos apartados que en el Reglamento 1/2003 están referidos a la Red europea de autoridades de competencia, así como en la Comunicación de la Comisión sobre la cooperación en la red de autoridades de competencia.

14 Acerca de las cuales se ha referido la Unctad (2013, pp. 4-17). El documento se encuentra disponible para consulta en: http://unctad.org/meetings/es/SessionalDocuments/ciclpd21_es.pdf

15 Conformada por las autoridades públicas nacionales, la Comisión y la Autoridad de Vigilancia EFTA (European Free Trade Association Surveillance Authority), siendo un precedente de la Red europea de autoridades de competencia, que en todo caso debe ser valorado, no solo por lo que realizó con antelación a la aparición del Reglamento 1/2003, sino por propiciar el escenario para el debate, a pesar de no tener un marco legal formal que la soporte. Sin olvidar su relevante papel, obtenido, como fruto de la independencia con la que cuenta al no estar controlada por la Comisión (Brammer, 2009, p. 112).

16 Tal y como también lo tienen los Tribunales de los Estados miembros en la Association of European Competition Law Judges.

17 Queda claro tras la elaboración de un paralelo entre los dos "conjuntos", que la existencia de ambos es pertinente y enriquecedora, toda vez que la Red Europea de Autoridades de Competencia centra sus recursos en las preguntas que se suscitan respecto del enforcement de los artículos 101 y 102 del Tratado, mientras que la Asociación de Autoridades de Competencia Europeas ha tenido una posición muy activa en la necesaria cooperación que se requiere en las concentraciones "plurijurisdiccionales", estructurando un manual de procedimientos para afrontar dichas situaciones. El desarrollo detallado de las particularidades de este "colectivo", puede encontrarse en Dabbah, M., (2010), International and comparative competition law, (pp. 204-208), Nueva York, Cambridge University Press.

18 El ámbito y las características de la Red europea de autoridades de competencia puede consultarse en Cengiz, F. (2010). Multi-Level Governance in competition Policy: The European 
ha resultado sencillo para la Comisión como eje central de la política de competencia comunitaria, así como para todos los demás "integrantes" de naturaleza pública, comprender la enorme relevancia que tiene la Red en la defensa de la competencia europea (Dekeyser y Jaspers, 2007, pp. 1622), y por lo tanto plantear y disponer los instrumentos idóneos para que efectivamente se cumpla el objetivo para el cual fue "instituida". ${ }^{19}$

Prueba de ello es -por nombrar la iniciativa de mayor alcance- el soporte informático o intranet que ha sido prioridad del conjunto de autoridades de competencia en la UE desde antes de la entrada en vigor del Reglamento $1 / 2003,{ }^{20}$ al ser entendida como una herramienta idónea y eficaz con la cual favorecer los principios de uniformidad, coherencia y asignación efectiva de recursos, que deben ser intrínsecos a la defensa de la competencia comunitaria.

Razón por la cual tras varios avatares de importancia, la mencionada intranet y otros instrumentos de naturaleza tecnológica, que también fomentan el trabajo coordinado, ${ }^{21}$ se encuentran ahora en disposición de las autoridades integrantes de la Red, actuando como componentes fundamentales

Competition Network, European Law Review, 35, (pp. 662-665), y Gerard, D. (2013). The ECN Network antitrust enforcement in the European Union, en Lianos, Ioannis y Géradin, Damien (edit.), Handbook on European Competition Law, (pp. 4-6).

19 Whish (2008, p. 283), explica que hay una fluidez real al interior de la Red que no solo se observa en la "evolución telemática" de las comunicaciones, sino que se escenifica en una variedad de encuentros programados, como el de: (i) los directores de las autoridades nacionales, que se encuentran una vez al año para discutir las circunstancias puntuales de mayor relevancia respecto de la política de competencia al interior de la Red; (ii) los de los oficiales de las distintas autoridades, quienes se encuentran cuatro veces al año en reuniones plenarias de la Red; (iii) los de los grupos de trabajo, donde se discuten cuestiones horizontales o transversales; y (iv) los de los subgrupos sectoriales donde se tratan aspectos concretos (energía, servicios financieros, etc.).

20 Así puede verse en el discurso de Schaub (2001). Texto disponible para consulta en lengua original en: http://ec.europa.eu/competition/speeches/text/sp2001_031_en.pdf; y en Paulis, E. (2001), Coherent Application of EC competition rules in a system of parallel competences, en Ehlermann, Claus-Dieter y Atanasiu, Isabela (edit.), European Competition Law Annual 2000: the modernisation of EC antitrust policy, (p. 407). Oxford, Hart Publishing.

21 Además de la Intranet, es prioridad en el seno de la Red y en el seno de la Comisión como principal autoridad de la misma otorgar, con la mayor transparencia, publicidad acerca de los asuntos que han sido objeto de la compenetración y colaboración entre autoridades, por lo que en el sitio web de la Comisión es posible encontrar referencia del número de procesos que se han suscitado en aplicación de las normas de libre competencia comunitarias, así como cuántos de ellos han sido iniciados por las autoridades nacionales de competencia. En lo referido al tema consultar, Daly, A. (2011), The Legality of deep packet inspection, en International Journal of Communications Law \& Policy, (14), (pp. 3-11), 
de la compenetración efectiva de facultades entre Enforcement Bodies, ${ }^{22}$ sin los cuales la tarea de protección de los mercados comportaría un esfuerzo excesivo difícilmente abordable de forma aislada o independiente.

Hasta cierto punto, la Red Europea de Autoridades de Competencia subsiste gracias a instrumentos como los descritos (Mataija, 2010, p. 77), aunque de igual modo requiere de la disposición de herramientas de tipo jurídico que además de justificar el uso de aquellos elementos telemáticos, tomen en cuenta los diversos niveles de cooperación y armonización de competencias que apareja la Red, toda vez que la configuración de colaboración interinstitucional no es siempre homogénea, pues al vincular a la Comisión Europea es de carácter vertical ${ }^{23}$ y al vincular relaciones cooperativas entre autoridades análogas del nivel nacional es horizontal.

Por lo que a continuación se expondrán las características de esa cooperación vertical y horizontal nombrada (Gerard, 2013, pp. 190-210), no sin antes manifestar que el listado de instrumentos cooperativos a enunciar no es ni mucho menos restrictivo, debido a que pueden emerger nuevas formas de colaboración gracias a las nuevas características del mercado y del sistema jurídico comunitario.

\subsection{La cooperación vertical}

La dimensión vertical de la cooperación entre autoridades de competencia, es aquella que se configura cuando la colaboración involucra dos niveles diversos, como el europeo, representado por la máxima autoridad

22 Si bien en el Reglamento y en la Comunicación sobre cooperación en la red de autoridades de competencia nada se dijo acerca de los métodos explícitos de comunicación entre los integrantes de la Red, en la práctica los oficiales de la Autoridad Comunitaria de Competencia han dejado claro que desde el mismo momento de la entrada en vigor del Reglamento 1/2003, ha sido dispuesto un soporte informático en condiciones para gestionar la comunicación entre autoridades, y que el mismo funciona de una forma óptima y efectiva (Burnside y Crossley, 2004, pp. 25 y ss.; Whish, 2008 , p. 262) La Intranet es la que permite que el flujo de información, sea cual sea el precepto legal que lo origine, se suscite, ya que soluciona los problemas temporales y espaciales de antaño, y permite centralizar y trasladar eficazmente todo el material de relevancia.

23 Siendo igualmente importante en este tipo de cooperación vertical la trayectoria cooperativa, referida al sentido en el cual se encamina la relación de "asistencia" entre las autoridades involucradas, toda vez que la colaboración puede ser requerida y/o delegada por la máxima Autoridad Comunitaria, generando una actuación particular de la Autoridad Nacional en busca de satisfacer la necesidad que un asunto ha presentado en sede de la Comisión Europea, pero igualmente puede ser solicitada por una Autoridad del nivel nacional y respondida por parte de la Comisión. 
de competencia comunitaria, y el nacional, vinculado con las autoridades nacionales de competencia de los Estados miembros de la Unión Europea.

Este tipo de cooperación, además de necesaria, es imperativa, pues permite trasponer a la realidad y conciliar, por medio del empleo de instrumentos idóneos, los intereses e intenciones que las autoridades de diversos niveles pueden tener en lo referido a la defensa de la competencia comunitaria. Lo cual resulta imprescindible para el sistema concurrencial europeo, pues si bien existe una identidad en los propósitos y en las inquietudes que las autoridades involucradas priorizan en el proceso de protección de los mercados, puede resultar también frecuente que se presenten diferencias de opinión acerca de los mecanismos adecuados para alcanzar sus metas (Mataija, 2010, p. 79-80), máxime, cuando una de las autoridades involucradas busca defender intereses supranacionales y la otra autoridad busca defender intereses internos de un Estado (Daujotas, 2011, p. 4).

No siendo fácil la tarea de establecer una base intelectual y de comunicación entre las autoridades de distintos niveles, que permita garantizar en mayor proporción la obtención de los objetivos comunes, el Reglamento 1/2003 ha venido a aportar un sistema de cooperación que intenta responder a muchos de los posibles choques entre las mencionadas autoridades, aunque no desarrolla de forma taxativa -caso por caso, atendiendo a todas las posibles coyunturas- el marco en el cual se debe enmarcar la cooperación vertical.

Solo es posible hallar alusiones acerca de las formas de cooperación entre la Comisión y las autoridades nacionales de competencia en algunos pocos apartados del Reglamento 1/2003, verbigracia en los numerales segundo y quinto del artículo 11, ya que los numerales restantes del mencionado apartado desarrollan otro tipo de instrumentos que no pueden ser considerados cooperativos, como lo son los mecanismos de control con los que cuenta la Comisión para monitorear la aplicación que realizan las autoridades nacionales de competencia de los Estados miembros. ${ }^{24}$

24 No comparte esta óptica Pace (2007, p. 274), toda vez que interpreta que solo el numeral quinto del artículo 11 del Reglamento 1/2003 puede ser entendido como un instrumento de cooperación vertical, ya que el numeral segundo, desde su punto de vista, no debe ser catalogado como un mecanismo idóneo de colaboración y compenetración entre Enforcement Bodies, sino como la primera etapa del control que pueden ejercer las autoridades nacionales de competencia sobre la labor de aplicación realizada por la Comisión. 
De tal forma, en ausencia un marco legal inequívoco que unifique los mecanismos de cooperación vertical, y existiendo aún aspectos por definir en lo que respecta a la Red europea de autoridades de competencia, es necesario acudir también a la Comunicación sobre la Red y a la doctrina, para definir los instrumentos cooperativos puestos a disposición de la Comisión Europea y las autoridades nacionales. Surgen de este análisis tres instrumentos que merecen ser resaltados a continuación.

\subsubsection{La consulta}

Este instrumento de cooperación se encuentra estipulado en el numeral quinto del artículo 11 del Reglamento 1/2003. Hace referencia a la posibilidad que tienen las autoridades nacionales de competencia de los Estados miembros de consultar a la máxima Autoridad Comunitaria acerca de cualquier asunto que involucre la aplicación de la normativa de libre competencia comunitaria. ${ }^{25}$

Tal y como lo establece el mencionado apartado, en virtud de este instrumento cooperativo se le otorga a las autoridades nacionales la posibilidad de dirigirse a la Comisión, en busca de que esta última -como encargada de la política de competencia europea- exponga su postura acerca de un asunto particular y realice los comentarios que estime pertinentes; tanto en los casos en los cuales la aplicación de la normativa de libre competencia comunitaria sea el epicentro del asunto, como cuando su grado de implicación sea menor.

El mecanismo cooperativo enunciado busca que las autoridades administrativas nacionales le den continuidad a la doctrina comunitaria, adaptándola a los asuntos particulares a su cargo y fortaleciendo el principio de uniformidad en materia de competencia. ${ }^{26}$

25 De relevancia al respecto, por ser fallos que desarrollaron el instrumento de consulta: la Sentencia del Tribunal de Justicia de la Unión Europea, de 18 de septiembre de 1992, Automec Srl Vs. La Comisión de la Unión Europea, asunto T24/90; así como el asunto BEMIM Vs. La Comisión. Siendo a su vez uno de los precedentes principales de este mecanismo, en razón de haberle otorgado desde su aparición un asidero formal, la Comunicación de la Comisión relativa a la cooperación entre la Comisión y las autoridades de competencia de los Estados miembros para el tratamiento de determinados asuntos incluidos en los artículos 81 y 82 del Tratado CE (actuales artículos 101 y 102 del Tratado), de 15 de Octubre de 1997, 97/C 313/03, publicada en el Diario Oficial C313 de la fecha enunciada.

26 Apartado 22 del Reglamento 1 del año 2003 y el numeral segundo del artículo 16 del mismo instrumento. 
En ese sentido, con tan loable objetivo, la doctrina ha apoyado el instrumento en comento y ha aplaudido que todo el sistema administrativo de defensa de la competencia tenga a su disposición una herramienta cooperativa de tan largo alcance. No obstante, ha manifestado tener serias dudas acerca del alcance de la figura, ya que como parte de la aplicación de las normas de libre competencia comunitarias por parte de los jueces, ${ }^{27}$ les parece que la regulación europea ha impuesto límites que entorpecen en cierta medida el uso de la consulta por parte de los tribunales nacionales, a pesar de los importantes excedentes que generaría otorgar a los jueces este poder. De acuerdo a su percepción, no resulta favorable para la defensa de la competencia europea esta diferenciación, ya que los jueces de los Estados miembros también pueden poner en peligro la uniformidad del sistema, haciendo más que necesario tener a su disposición instrumentos que les permitan prevenir contradicciones surgidas del tenor de sus resoluciones (Concepción Rodríguez, Gimeno-Bayón Cobos \& Rodríguez, 2004; Guillén Camarés, 2013).

En el numeral primero del artículo 15 del Reglamento 1/2003 es posible hallar luces acerca de la mencionada inquietud de la doctrina. En aquel apartado se encuentra desarrollada la relación cooperativa entre la Comisión y los Tribunales nacionales, y se establece que la consulta que pueden realizar estos últimos a la Autoridad comunitaria se circunscribe exclusivamente a los procedimientos en los cuales el eje principal sea la normativa de libre competencia comunitaria, sin extenderse -como sucede en el caso de las autoridades nacionales- a cualquier asunto que involucre, así sea de forma somera y/o trasversal, la aplicación de dichas normas.

La explicación del tratamiento dispar expuesto, la ha encontrado algún sector de la doctrina especializada en los distintos roles que tienen las autoridades administrativas nacionales de competencia y los Jueces de los Estados miembros en el sistema de defensa de la competencia comunitario.

27 Desarrollo de la participación de los jueces nacionales en la aplicación de las normas de libre competencia comunitarias en: Komninos, A. (2007b), Modernisation and Descentralisation: Retrospective and Prospective, en G. Amato \& C. D. Ehlermann (edit.), EC Competition Law. A Critical Assessment, Oxford, Hart Publishing; Ortiz Baquero, I. (2001), La aplicación privada del derecho de la competencia. Los efectos civiles derivados de la infracción de las normas de libre competencia, Madrid, Wolters Kluwer; Wils, W. (2002), The Optimal Enforcement of EC antitrust Law, La Haya, Kluwer Law International; y Velasco San Pedro, L. \& Alonso Ledesma, C., et al. (Eds.) (2011). Private enforcement of competition law, Valladolid, Lex Nova. 
De acuerdo a su percepción, en la UE se ha venido haciendo un esfuerzo especial por otorgar a las autoridades nacionales suficientes poderes que les permitan, de ser necesario, reemplazar -en lo referido a la aplicación de los artículos 101 y 102 del Tratado- a la Comisión Europea, mientras que la participación de los jueces se soporta en otro tipo de objetivos (Holmes y Lennon, 2004; Soto Pineda, 2013b; Jones, 2003; Vez Pazos, 2009; Van Bael y Bellis, 2010).

De tal modo, si bien se comparte aquella percepción, resulta pertinente resaltar otro tipo de argumentos que explican la diferencia entre las consultas de origen administrativo y judicial. Así, por ejemplo, no puede desconocerse que la integración en la UE ha generado una cultura concurrencial, que ha incrementado exponencialmente el número de asuntos a resolver por los distintos Enforcement Bodies. ${ }^{28}$ Adicionalmente, que se otorgue un poder general a los jueces nacionales, que se equipare a la posibilidad de consulta en manos de las autoridades nacionales, podría repercutir en una carga inmensa para la Comisión, que estaría abocada a responder continuamente a consultas basadas en aspectos que van más allá del área cubierta por la defensa de la competencia en la UE.

A estos argumentos deberían aunarse algunos otros que permitan justificar, así sea en parte, el tratamiento dispar entre ambos instrumentos de consulta, como lo son: (i) el número de autoridades nacionales de competencia empoderadas para solicitarla, el cual difiere proporcionalmente del número considerable de jueces nacionales ahora capacitados para aplicar los artículos 101 y 102 del Tratado; (ii) la identidad que existe entre la Comisión y las autoridades nacionales en razón de su similar naturaleza; (iii) la presumible asignación de recursos innecesarios que la Comisión debería poner en funcionamiento para hacerle frente a consultas que tengan como origen a un Tribunal Nacional, entre otros.

\subsubsection{La materialización de diligencias}

Este instrumento de cooperación se configura cuando la Comisión en uso de los poderes de investigación que le han sido conferidos "delega", o

28 Efecto común desencadenante de la litigiosidad en materia de libre competencia. Sobre la cual se ha referido Lande (2004) y también se destacan los trabajos de Buccirossi, Ciari, Duso, Spagnolo y Vitale, (2011); Mackenrodt (2008) y Polster (2008). 
simplemente solicita a una autoridad administrativa nacional de competencia, en virtud de las facultades de investigación que le han sido conferidas, que realice y conduzca una diligencia en su nombre en el territorio del Estado miembro al cual pertenece. ${ }^{29}$

El numeral segundo del artículo 22 del Reglamento 1/2003 desarrolla esta herramienta cooperativa, ${ }^{30}$ que resulta indispensable para enfrentar situaciones de envergadura que comportan el desmantelamiento de conductas de gran talante, como los carteles. La compleja y vanguardista estructura que adoptan estos últimos para mantener en secreto los acuerdos contra legem contraídos entre sus participantes requieren de acciones eficaces por parte de las autoridades administrativas, con el objetivo de sorprender a las empresas infractoras (Unión Europea. Comisión Europea, 2003; Tierno Centella y Peña Castellot, 2002; Polster, 2008; Pastor, 2005; Flynt Blanck, 2002). ${ }^{31}$ Tal y como sucede en las inspecciones simultáneas, sorpresa (Whish, 2008; Korah, 2007) que gracias al mecanismo de cooperación en comento, han presentado resultados estupendos en los últimos 10 años.

La Comisión -tanto si tiene como objetivo aprovechar los recursos de las autoridades nacionales en circunstancias como la descrita en el párrafo anterior, como si solicita la realización de la inspección ${ }^{32}$ o la asistencia en la diligencia en otro tipo de motivaciones ${ }^{33}$ - cuenta con la posibilidad, cada vez más empleada, de solicitar esta colaboración que es manifestación

29 El grado de compromiso de las autoridades nacionales de competencia, se comprueba gracias a instrumentos de cooperación como el presente, tal y como se encuentra estipulado en el numeral quinto del artículo 20 del Reglamento 1/2003. Siendo un poder en virtud del cual, en búsqueda por llevar las infracciones a la normativa antitrust a su fin, los agentes y oficiales de dichas autoridades, serán empoderados para poner en marcha su colaboración, con las atribuciones que están estipuladas en el numeral segundo del mencionado artículo.

30 Para ahondar acerca de las bondades que la doctrina percibe en ella, puede verse: Korah, V. (2007), An introductory guide to EC Law and practice, (p. 262). Oxford \& Portland, Hart Publishing.

31 Son igualmente relevantes los comentarios de Bellamy y Child (1996), y en referencia a la discriminación de precios y la respuesta institucional los de Poehls Bustos (2013).

32 Acerca de la inspección, como medio idóneo y de gran efectividad para desmantelar conductas anticompetitivas en la Unión Europea, consultar: Soto Pineda, J.A. (2013a); A propósito de un elemento esencial de la defensa de la competencia en Europa: las facultades de investigación de la Comisión en materia de inspección", en Revista de Ciencias jurídicas y sociales, Foro nueva época, 16(1), (pp. 165-212).

33 Como requerir asistencia extraordinaria al entender que no cuenta con los recursos humanos suficientes para afrontar con garantías una inspección realizada en una empresa o asociación de empresas de gran tamaño; por solicitar la realización de una diligencia en específico en los idiomas apropiados y en razón de la cultura jurídica correcta; por querer aprovechar el conocimiento del territorio que puede proporcionar la Autoridad de aquel Estado, entre otras. 
de la cooperación de carácter "vertical-ascendente" que algún sector de la doctrina entiende, se configura en este tipo de circunstancias. ${ }^{34}$

Por ser un aspecto de relevancia contrastada que influye en la puesta en práctica del mismo, es necesario acotar que una vez realizada la petición o delegación de esta atribución investigadora por parte de la Comisión, el ejercicio de las facultades de aquellos oficiales de la autoridad nacional de competencia encargados de realizar la diligencia pertinente, deberá llevarse a cabo en atención a las normas del Estado miembro y de acuerdo con los lineamientos que el derecho interno haya previsto para la actuación investigadora de la autoridad nacional de competencia correspondiente. ${ }^{35}$

En razón de aquello, queda claro que aunque la Comisión es la solicitante de la actuación de la autoridad nacional de competencia, los parámetros que servirán de guía a esta última deberán ser extraídos del derecho nacional. En este último, deben estar consignadas las condiciones de los poderes de investigación con los que cuenta la autoridad doméstica, los principios en los cuales se basan, ${ }^{36}$ los procedimientos a seguir para adherir transparencia al ejercicio de ellos, las garantías que son puestas a disposición de las empresas involucradas, entre otros.

34 Especial, la opinión de Pace (2007).

35 Lo que no debe significar una pugna con los intereses comunitarios, o la producción de instrumentos legales o similares que imposibiliten este y otros mecanismos de cooperación, ya que los Estados miembros, en la labor de estructuración de las condiciones en las cuales su autoridad de competencia deberá poner en marcha sus poderes de investigación, no puede desconocer la obligación intrínseca que le impone el derecho Comunitario de respetar los principios de la Unión y garantizar, en la medida de lo posible, que las acciones emprendidas por la Comisión sean efectivas. Tal y como puede verse en la Sentencia del Tribunal de Justicia de la Unión Europea, de 21 de septiembre de 1989, Hoechst A. G. Vs. La Comisión de la Unión Europea (en lo sucesivo Hoechst Vs. La Comisión), asuntos acumulados $46 / 87$ y $227 / 88$, apartados 33 y 34 ; y en la sentencia del Tribunal de Justicia de la Unión Europea, de 22 de octubre de 2002, Roquette Frères SA Vs. Directeur géneral de la concurrencede la consommation et de la répression des fraudes, y la Comisión de la Unión Europea (en lo sucesivo Roquette Fréres), asunto C-94/2000, en sus apartados 34 y 35; toda vez que son asuntos de inmensa relevancia que delimitaron las bases esenciales de este tipo de atribuciones cooperativas "delegadas" en el campo investigador.

36 El reconocimiento del principio de derecho Comunitario en virtud del cual se protege a los particulares de la intervención desproporcionada, excesiva y arbitraria efectuada por las autoridades públicas es uno de los pilares del ejercicio de atribuciones de investigación por parte de las autoridades nacionales de competencia, sin importar si son resultado de una delegación realizada por la Comisión o fruto de sus propias atribuciones. Toda vez que debe garantizarse el respeto de dicho principio en todas las circunstancias, desde el principio de la diligencia, hasta su finalización. Hoechst A. G. Vs. La Comisión, apartados 19, 33, 34 y 35 y Roquette Frères, apartados 27, 28, 36 y 37. 


\subsubsection{El tránsito vertical de información}

La circulación de información entre las muchas autoridades empoderadas -en virtud de los cambios surgidos después el año 2003- para aplicar las normas de libre competencia comunitarias es una de las principales razones en las cuales se basó el "legislador" europeo para otorgar a Enforcers culturalmente desligados de dicha tarea, las herramientas necesarias para contribuir con el proceso de modernización, descentralización y pluralización de la defensa de la competencia en la UE. ${ }^{37}$

Gracias a las modificaciones que fueron adheridas al Reglamento $1 / 2003$, a día de hoy es posible comprobar cómo se ha potenciado el flujo de material documental en el seno de la Red Europea de Autoridades de Competencia, fomentando el uso de dicho material, tanto para iniciar investigaciones en contra de empresas o asociaciones de empresas, como también para comprobar transgresiones cometidas por aquellas (Pace, 2007, p. 285).

No obstante los excelentes resultados que ha traído aparejada la nueva dinámica de traslado informativo (Kekelekis, 2009, pp. 35-39), resulta posible hallar ciertos despropósitos e incongruencias que la doctrina ha identificado en este mecanismo cooperativo, generando divisiones de importancia en el campo procesal. Por ejemplo, se estima esencial enunciar la extrañeza que ha causado observar, que a pesar del deseo del sistema al completo de favorecer el tránsito informativo en el interior de la $\operatorname{Red}^{38}$ el Reglamento 1/2003 hubiese hecho importantes concesiones a favor de la Comisión referidas al traslado de información en comento. Siendo así, ya que fueron abolidos varios compromisos de información que le eran impuestos a la Comisión por parte del Reglamento 17/1962, en virtud de los cuales la máxima autoridad de competencia comunitaria estaba obligada a comunicar a las autoridades nacionales la iniciación de todos

37 Como puede observarse en el apartado 16 del Reglamento 1/2003, así como en el numeral primero del artículo 12 del mismo instrumento. Fundamentado a su vez por la doctrina en Dekeyser (2005, p. 161), Kris y De Smijter (2005, p. 161), y Reichelt (2005, p. 745).

38 Como efectivamente lo tiene en el Reglamento 1/2003, donde en su artículo 12 se encuentran los parámetros esenciales del intercambio de información entre la Comisión y las autoridades nacionales de competencia, así como también el efectuado por estas últimas entre ellas. Siendo un tema desarrollado a más profundidad en los numerales del 26 al 28 de la Comunicación sobre cooperación en la red de autoridades de competencia. 
los procedimientos a su cargo, sin importar si estaban dirigidos a la prohibición y sanción, a la adopción de medidas cautelares, a la aceptación de compromisos, a la adopción de decisiones de inaplicabilidad, a la retirada de un beneficio de exención por categorías, ${ }^{39}$ etc.

Con el Reglamento 1/2003, los compromisos de información a cargo de la Comisión se vieron reducidos, pues la obligación automática de remitir todo el material sobre un asunto particular a los organismos nacionales de naturaleza administrativa desapareció, dándole lugar a un envío de información más dosificado y sistemático, en virtud del cual la Comisión está obligada a transmitir solo las copias de los documentos que estime de mayor relevancia acerca de un asunto particular a su cargo. ${ }^{40}$ Adicionalmente, existe la posibilidad de que sea proporcionado más material, sólo en aquellos casos en los cuales las autoridades de los Estados miembros así lo soliciten y la Comisión esté de acuerdo con hacerlo, toda vez que esta última no está obligada a responder afirmativamente dicha petición en todos los casos (Van Der Woude, 2004, pp. 377-378).

La remisión de documentación en masa imperante en los tiempos del Reglamento 17, al parecer, no concedió las mejores sensaciones, ${ }^{41}$ pues su idoneidad para garantizar que las autoridades administrativas nacionales

39 Numeral primero del artículo 10 del Reglamento 17/1962, donde puede observarse que el compromiso de transmitir la información configuraba una obligación automática que debía cumplir la Comisión, toda vez que al expresar: "transmitirá sin demora", no se planteaba en el Reglamento 17 eventualidad alguna en virtud de la cual la máxima Autoridad Comunitaria pudiese abstraerse de remitir la información pertinente o de guardarse algún material específico, ya que con el texto enunciado quedaba claro que se debía enviar toda la documentación del asunto. Acerca de las decisiones que la Comisión Europea y las autoridades nacionales pueden tomar en el marco de un asunto concurrencial, Soto Pineda (2012, pp. 160-200 y 313 y ss.).

40 De relevancia sobre el tema, consultar: Union Europea, Tribunal de Justicia de la Unión Europea (Sala quinta). Sentencia C-36/92 P, Samenwerkende Elektriciteits-Produktiebedrijven NV (SEP) Vs. La Comisión de la Unión Europea, apartado35 (19 de May. 1994) texto disponible para consulta en: http://eurlex.europa.eu/LexUriServ/LexUriServ.do?uri=CELEX:61992J0036:ES:PDF

41 En parte porque se pretendía fortificar el respeto por el principio esencial de protección de los secretos negociables o comerciales en favor de las empresas, ahora mejor protegido y entendido por los Enforcement Bodies, debido a que debe ser gestionado con inmenso cuidado, pues por sí solo puede llevar a restringir la circulación de información en la Red Europea de Autoridades de Competencia, tanto en los casos en los que esté vinculada la Comisión, como en aquellos en los que no lo esté. En caso de que el tránsito informativo se muestre en capacidad de vulnerar dicho derecho, será necesario restringirlo. Esto último puede consultarse en: Unión Europea. Tribunal de Justicia de la Unión Europea (Sala quinta). Sentencia 53/85, AKZO Chemie BV Vs. La Comisión de la Unión Europea, apartado 28, (24 jun. 1986) y enUnión Europea. Tribunal de Justicia de la Unión Europea. Sentencia C-36/92 P, Samenwerkende Elektriciteits-Produktiebedrijven NV (SEP) Vs. La Comisión de la Unión Europea, (en lo sucesivo SEP Vs. La Comisión), apartado 36, (19 may. 1994). 
de competencia estuviesen siempre bien informadas, fue puesta en duda. Ello conllevó que se pusiera en marcha una iniciativa que se transpuso en el Reglamento 1/2003, dirigida a involucrar de forma efectiva, certera y puntual a las mencionadas autoridades en la resolución de asuntos relevantes, otorgándoles la posibilidad de -siempre que lo estimen pertinente- solicitar información adicional a aquella remitida por la Comisión.

Con dicha posibilidad, la doctrina ha entendido, tal y como se ha podido comprobar hasta la fecha, que las autoridades nacionales hacen un mejor uso de su poder, pues pasan de tener una posición pasiva más que todo dirigida al archivo de todo el material documental que les era remitido por la máxima autoridad de competencia comunitaria, a un enfoque activo en el cual por iniciativa propia buscan adentrarse en las situaciones particulares del caso, generando aportes que, con la realidad que imponía el Reglamento 17, no se presentaban.

De esta forma, se robustece la posición de la Comisión como figura central de la defensa de la competencia en la UE, pues con esa capacidad de decisión respecto de la información -otorgando o no el material solicitado- se le confiere a la autoridad comunitaria una especial discrecionalidad también en su relación de cooperación con los otros Enforcement Bodies, priorizando a su vez la protección de material susceptible, que en algunas oportunidades resulta pertinente resguardar en el seno de la Comisión. ${ }^{42}$

Así como se fortificó en lo referente a este tema el papel de la autoridad comunitaria, a la inversa, los deberes de las autoridades nacionales de competencia se vieron incrementados, pues ahora, con mayor fuerza que antaño, aquellas deben enlazar sus actividades con las de la Comisión Europea, remitiendo a esta última información en dos momentos puntuales que garantizan que: (i) el reparto de asuntos al interior de la Red europea de autoridades de competencia funciona fluidamente, ${ }^{43}$ así como que (ii)

42 Toda vez que el alcance del material informativo no es siempre el mismo. Por esta razón, la Comisión tiene el poder, y en todo caso el deber de solicitar, a las autoridades administrativas nacionales de competencia y a los Tribunales de los Estados miembros, garantías de que están en capacidad de proteger la información remitida, atendiendo a las condiciones particulares de cada pieza que configure el paquete documental (Van Bael y Bellis, 2010, pp. 1031-1033). Circunstancia aquella que no es ajena a otros sistemas jurídicos, relacionados o no con la defensa de la competencia, toda vez que la importancia radica en la capacidad de dar un uso transparente al material fruto de la tarea que llevan a cabo. Como así lo pone de manifiesto Vivanco Martínez (2008, pp. 371-398).

43 En razón de la remisión de información inicial, incluida en el numeral tercero del artículo 11 del Reglamento 1/2003. 
la Comisión tiene en todos los casos la oportunidad de expresar su óptica sobre el asunto en la etapa final del proceso. ${ }^{44}$

Ahondando sobre ello, es pertinente decir que el primer momento en el cual las autoridades nacionales deben remitir obligatoriamente información a la Comisión acerca del asunto particular es al inicio del procedimiento, antes de que se ponga en marcha medida de investigación alguna o, en su defecto, inmediatamente después de iniciadas las diligencias pertinentes; siempre y cuando el caso particular así lo haga necesario.

El segundo momento en la etapa final del procedimiento -pues en ella las autoridades nacionales deberán informar a la máxima autoridad comunitaria, por lo menos con 30 días de antelación a la adopción de la decisión- es saber cuál es la línea de acción que seguirán sobre un caso particular. Siendo irrelevante el marco de la resolución, pues el requisito tiene el mismo alcance si se ordena la prohibición y cese de la conducta, si se aceptan compromisos, o si se retira la cobertura otorgada por un reglamento de exención por categorías. ${ }^{45}$

De ahí que cada autoridad al tener motivado su fallo, deba remitir a la Comisión un sumario de la decisión prevista y esté obligada a proporcionarle asistencia en todo momento, especialmente si la autoridad comunitaria solicita copias de documentos centrales del caso, que entienda determinantes para confeccionar sus comentarios.

Sobre este instrumento de cooperación cabe acotar - para finalizar con el apartado referente a la cooperación vertical- que está influido por unos lineamientos esenciales que operan como salvaguarda en favor de las empresas y los particulares, en virtud de los cuales deben ser respetadas ciertas condiciones para que el tránsito de documentos y material se consume sin afectar los intereses que aquellos puedan tener sobre la información objeto de la cooperación entre autoridades.

De esta manera, dichos límites se configuran también de forma horizontal, operando de la misma forma tanto en los casos en los que la Comisión está vinculada, como en aquellos en que no lo está. En el apartado titulado

${ }^{44}$ Como resultado de la remisión de información final del numeral cuarto del artículo 11 del Reglamento 1/2003.

45 No estando incluidas las decisiones de desestimación, rechazo o sobreseimiento de un asunto particular (Daujotas, 2011, p. 24). 
"Límites al ejercicio del intercambio de información (horizontal y vertical) entre Enforcement Bodies" del presente artículo, se hará referencia a dichas salvaguardas una vez sean expuestas las demás particularidades del intercambio de información entre autoridades administrativas nacionales, toda vez que se ejecutan en las mismas condiciones.

\subsection{La cooperación horizontal}

La cooperación entre autoridades nacionales de competencia es fundamental para el sistema de protección del ecosistema competitivo europeo, toda vez que trasponer sin ella los objetivos que fueron incluidos en el Reglamento $1 / 2009$ y en el compedio de instrumentos comunitarios anexos a la realidad incluidos sería casi imposible.

Esta clase de cooperación de carácter horizontal es incluso más delicada que aquella que involucra a la Comisión Europea, debido a que implica la compenetración de autoridades del mismo nivel -el nacional- que se encuentran enlazadas entre sí, exclusivamente, gracias a la Red Europea de Autoridades de Competencia. La claridad que al proceso cooperativo trae la posición de privilegio de la Comisión, la simplicidad que aporta relacionarse en exclusiva con una sola autoridad y las facilidades en la interacción multinivel gracias a la provisión de instrumentos telemáticos dispuestos para favorecer la labor de control de la máxima Autoridad comunitaria, son algunas de las razones por las cuales resulta más sencillo en el ámbito europeo emprender la cooperación vertical que poner en marcha la cooperación de naturaleza horizontal (Geradin, Reysen y Henry, 2008).

El objetivo principal de este tipo de cooperación es esquivar a como dé lugar la doble asignación de recursos en torno a un mismo caso, potenciando que cada asunto particular en el cual la normativa de libre competencia comunitaria deba ser aplicada, sea conducido en términos de eficiencia por una sola autoridad.

Para la obtención de aquel derrotero, el Reglamento 1/2003 ha dispuesto tres mecanismos distintos que garantizan que aquel Enforcement Body mejor posicionado para llevar a cabo la aplicación de los artículos 101 y 102 en una circunstancia particular, sea quien efectivamente lo haga. Con el establecimiento de los tres instrumentos mencionados, en la Unión Europea se ha buscado, además de asegurar el "reparto" preceptivo men- 
cionado, (i) potenciar la colaboración en todos aquellos casos en los cuales las circunstancias particulares del asunto hagan necesaria la participación de autoridades homólogas de otros estados miembros, y (ii) solventar pugnas susceptibles de presentarse cuando dos o más autoridades se han hecho cargo de un mismo asunto. A continuación serán desarrollados los tres mecanismos dispuestos en el paquete de modernización del año 2003.

\subsubsection{El tránsito horizontal de información}

Este instrumento de cooperación es una innovación bien valorada que ha traído el Reglamento 1/2003, en razón de la cual la aplicación descentralizada de las normas de libre competencia puede ser llevada a cabo con suficientes garantías. A partir de este mecanismo, las autoridades nacionales de los Estados miembros, sin mediación de la Comisión, ${ }^{46}$ pueden intercambiar información de relevancia que esté en capacidad de facilitar la evaluación sobre un asunto particular que deban llevar a cabo. ${ }^{47}$

Tanto la parte final del numeral cuarto del artículo 11 del Reglamento $1 / 2003^{48}$ como el numeral primero del artículo 12 del mismo instrumento ${ }^{49}$ son pilares de este mecanismo de cooperación, pues otorgan a las autoridades nacionales de competencia un poder que no estaba comprendido en el Reglamento 17, dirigido a favorecer el intercambio de información, incluso de carácter confidencial (bajo el cumplimiento de ciertos límites que se analizarán en apartados posteriores del presente documento).

En el Reglamento 1/2003, este instrumento de cooperación de carácter horizontal permite delimitar tres momentos diversos en los cuales

46 Que ha sido por defecto el catalizador de la información en razón de la relación de gran verticalidad y centralización que se ha fomentado en el sistema de defensa de la competencia en la UE hasta la aparición del Reglamento 1/2003. (Pace, 2007, p. 276).

47 Lo cual en ningún caso significa que las autoridades nacionales de competencia puedan escapar del control de la Comisión.

48 “(...) Las autoridades nacionales de competencia podrán asimismo intercambiarse la información necesaria para evaluar el asunto que estén instruyendo al amparo de los artículos 81 u 82 del Tratado." (Comunidad Europea, 2003, artículo 11).

49 “(... la Comisión y las autoridades de competencia de los Estados miembros deberán estar facultadas para procurarse entre sí y utilizar como medio de prueba todo elemento de hecho o de derecho, incluida la información confidencial." (Comunidad Europea, 2003, artículo 12). 
se impulsa su ocurrencia, ${ }^{50}$ basados en la etapa del "proceso" en la que se consuma el tránsito informativo. El primer "momento procesal" está adherido al numeral cuarto del artículo 11. En virtud de él, se anima a las autoridades nacionales para que, no habiéndose realizado un reparto del asunto, se contacten entre sí y, con la ayuda de todo el material informativo que puedan integrar de forma conjunta, decidan cuál de ellas se encuentra en mejor posición para hacerse cargo del caso. ${ }^{51}$

Existe a su vez un segundo "momento procesal" dispuesto en los mencionados artículos 11 y 12 del Reglamento, conforme al cual se fomenta el tránsito de información, incluso tras la etapa de reparto. Con motivo de este estímulo -que ha presentado resultados perfectibles (European Competition Network, 2010)-, el tránsito informativo puede generarse también cuando una autoridad administrativa nacional, tras la etapa de contactos en la ronda de reparto, ya se ha hecho cargo del caso. Los apartados mencionados, en ese sentido promueven que de forma continuada, y hasta la decisión del asunto, la información cambie de manos de forma fluida -con apenas obstáculos-, toda vez que es precisamente en la etapa intermedia del proceso, en la cual se reúnen los instrumentos probatorios idóneos y las herramientas fundamentales para llevar la infracción al cese. ${ }^{52}$

Este mecanismo de cooperación no se restringe a aquellas eventualidades, pues surge igualmente en razón de un tercer momento procesal, detallado en el numeral primero del artículo 22 del Reglamento 1/2003. A través de este una autoridad nacional puede llevar a cabo una inspección o diligencia en su territorio en nombre de una autoridad nacional foránea,

50 Lo cual no excluye la aparición de nuevas eventualidades y circunstancias que, de acuerdo a la evolución de la cultura jurídica en la UE, hagan necesario un marco de actuación conjunto entre los Enforcement Bodies de carácter nacional y comunitario.

51 Como puede verse en el apartado 26 de la Comunicación sobre cooperación en la red de autoridades de competencia (2003), donde queda claro que la importancia de los parámetros descritos en el artículo 12 del Reglamento 1/2003 es inmensa, ya que el reparto coherente de asuntos se basa en que las autoridades involucradas hagan uso efectivo de las herramientas que ahora proporciona la Red europea de autoridades de competencia.

52 Un desarrollo, en opinión de quien escribe, parcial, acerca de las condiciones y lineamientos a seguir por los distintos Enforcement Bodies para llevar a cabo el intercambio informativo, puede encontrase en la Comunicación sobre cooperación en la red de autoridades de competencia (2003), entre sus apartados 26 y 27, toda vez que el apartado 28 desarrolla salvaguardas referentes a la utilización de la información que no rigen las formas mediante las cuales el material cambia de manos al interior de la Red. 
previa solicitud de esta última. ${ }^{53}$ Siendo la información recolectada, igualmente, objeto de la transmisión entre Enforcers nacionales, ya que a pesar de que el material sea obtenido como resultado de una colaboración prestada a una autoridad ubicada en una jurisdicción distinta, dicha información, para poder ser utilizada como prueba por la autoridad nacional solicitante, debe cambiar de manos de acuerdo a las condiciones del artículo 12 del Reglamento. ${ }^{54}$

Si bien los parámetros descritos confieren una alta evolución a las relaciones entre las autoridades nacionales y las fomentan, asombra que en el Reglamento y en la Comunicación sobre la Red hayan quedado algunos puntos sin desarrollar en relación con el tránsito informativo entre las mencionadas autoridades y que nada se haya expuesto en aquellos instrumentos acerca de los marcos de comportamiento imperativos a respetar por parte de una autoridad nacional de competencia, en momentos cruciales de la relación cooperativa -concreta o en potencia- con otro Enforcer.

Así por ejemplo, de la ausencia de dichos parámetros en los instrumentos enunciados, se extrae que las autoridades nacionales de competencia no están obligadas a responder afirmativamente en todas las ocasiones a las solicitudes de intercambio de información, evidencia o material que les hagan sus pares de otros Estados miembros.

En el mismo sentido, no deja de sorprender que una autoridad nacional de competencia al iniciar un procedimiento, no deba notificar a las autoridades nacionales de competencia -presumiblemente interesadas en el asunto particular- acerca del proceso a su cargo, y llama la atención, incluso con más ahínco que aquello, el hecho de que una vez redactado un proyecto de decisión por parte de una autoridad administrativa nacional

53 Sobre el tema, consultar: Creus Carreras, A. G Amador Peñate, O. (2005), Procedimiento administrativo ante la Comisión Europea y control jurisdiccional del TJCE, J. M. Beneyto PérezCerdá y J. M. Gonzalez Orús (direct.), Tratado de derecho de la competencia. Unión Europea y España, (pp. 758-760), Madrid, Bosch; Furse, M. (2006) Competition Law of the EC and UK, (p. 90), Nueva York, Oxford University Press.

54 Acerca de las particularidades del tránsito informativo que se da como resultado de la solicitud efectuada por una Autoridad Nacional de competencia, de materialización de una diligencia, a otra autoridad Nacional, así como haciendo énfasis en la importancia que tiene dicho tránsito cuando sólo ha sido asignado a una Autoridad el asunto. Para profundizar en este tema, se recomienda la lectura de Widegren, M. (2004), Consultation among Members within the Network, en C. D. Ehlermann \& I. Atanasiu (edit.), European Competition Law Annual 2002: Constructing the EU Network of Competition Authorities, (pp. 419-424), Oxford, Hart Publishing. 
de competencia, aquel no deba, por obligación, ser facilitado o remitido en un marco temporal específico, a otra $\mathrm{u}$ otras autoridades interesadas.

Si bien se desearía que las incongruencias sobre el tránsito informativo entre autoridades nacionales hubiesen sido resueltas en los años de vigencia del Reglamento 1/2003 y que dichas problemáticas se restringieran a los escenarios descritos previamente, resulta que en adición a dichas falencias, se presenta una de gran talante que involucra otros principios de colaboración, los cuales no solo implican la posible asignación de recursos dobles por parte de varias autoridades nacionales de competencia a un mismo asunto, $^{55}$ sino incrementan la posibilidad -altamente peligrosa- de que las infracciones a los artículos 101 y 102 del Tratado queden sin resolver.

Ejemplo de ello es la incoherencia que se percibe al observar que en el Reglamento 1/2003 y en la Comunicación sobre la Red se intentó dejar claro que una autoridad nacional puede solicitar asistencia a otra para que lleve a cabo en su territorio una diligencia dirigida a descubrir la transgresión, pero, a su vez se guardase silencio acerca de la obligación de asistencia por parte de la autoridad requerida; esto permite concluir que no se puede coaccionar a esta última para que lleve a cabo las inspecciones o las diligencias que le han sido solicitadas.

En cualquier caso un absurdo que resulta difícil de explicar, toda vez que no se encuentra razón clara para sustentar que tanto el Reglamento como la Comunicación, hubiesen guardado silencio al respecto, tal y como lo define una parte importante de la doctrina, que a su análisis ha aparejado críticas acerca de dicha incongruencia, con la cual se promueve la cooperación, pero sin fortificarla, generando un escenario en el cual alcanzar la mutua y regular colaboración horizontal es muy difícil, puesto que se involucran grados de discrecionalidad con capacidad para generar la tan indeseada doble asignación de recursos.

A pesar del desacuerdo, y entendiendo que la obligatoriedad para remitir información debería no solo configurarse cuando la Comisión esté involucrada, sino también cuando la cooperación es solicitada por una autoridad administrativa nacional, se deduce que tal vez el objetivo

55 Que tal y como ya se expuso, se configura como resultado de la ausencia de una obligación explícita a cargo de las autoridades nacionales de competencia, de proporcionar información a otras autoridades del mismo nivel de otros Estados miembros, notificar a sus pares el inicio de un proceso o remitir un proyecto de decisión. 
al guardar silencio sobre ello, fue el de dejar al arbitrio de las autoridades nacionales de competencia la definición del nivel de compromiso que tendrían con la Red. ${ }^{56}$ Aunque esta concepción tiene algo de sentido, no es del todo satisfactoria, pues la realidad en este tipo de circunstancias ha permitido demostrar que de no existir normas de obligatorio cumplimiento que regulen la forma y condiciones en las cuales la cooperación va a verse transpuesta a la realidad, la colaboración interinstitucional difícilmente se configurará. ${ }^{57}$

Sea cual sea la teoría, y entendiendo que debería potenciarse la claridad de aspectos como los enunciados, la realidad es que las autoridades nacionales de los Estados miembros han actuado consecuentemente con los objetivos de la reforma del año 2003 y han hecho muchos esfuerzos por demostrar que su grado de implicación con la Red Europea de Autoridades de Competencia es alto; Esto ha implicado que la información, a día de hoy, se mueva con gran soltura entre las diversas autoridades (Schaub, 2001, pp. 1-8) y que el trabajo conjunto entre Enforcers sea suficientemente fluido.

\subsubsection{Límites al ejercicio del intercambio de información (horizontal y vertical) entre Enforcement Bodies}

El uso que las autoridades de competencia pueden dar a la información que les es remitida por otro Enforcement Body tiene ciertos límites y salvaguardas, que se encuentran dispuestos en los numerales segundo y tercero del artículo 12, y el artículo 28 del Reglamento 1/2003, así como

56 Siendo prueba de ello que deja en manos de la normativa nacional temas tales como las condiciones en las cuales será llevada a cabo la transmisión de información a la Comisión, cuando dicho material sea obtenido en aplicación de la legislación de carácter penal en el Estado miembro, tal y como puede verse en la Unión Europea. Tribunal de Justicia de la Unión Europea. Sentencia C-407/04 P, Dalmine SpA Vs. La Comisión de la Unión Europea, apartado 62, (25 ene. 2007).

57 Ejemplo de ello es la normativa tributaria en la UE e incluso en el mundo, que tiene como figura principal los acuerdos entre Estados, dirigidos a evitar la evasión de impuestos, doble imposición y similares. En razón de los cuales las Administraciones Tributarias involucradas tienen un compromiso tácito de colaboración y tránsito informativo, que en la realidad no se configura fácilmente y sí de forma excepcional, pues aspectos e intereses que van más allá del objetivo recaudatorio influyen e imposibilitan en múltiples ocasiones la cooperación. (Fitzgerald, 2002, pp. 67-81). Para profundizar en este tema, consultar Arias E. E Isaác G. (2011), Aspectos a considerar para un efectivo intercambio de información tributaria, en Manual CIAT para la Implementación y Práctica del Intercambio de Información para Fines Tributarios, año XXVI, (159). 

la Red de Autoridades de Competencia (2003).

Tras la lectura de los apartados mencionados es posible percibir cierta contradicción ${ }^{58}$ surgida del diverso nivel de rigidez con el cual las dos disposiciones abordan el tema del intercambio de información entre autoridades, a pesar de formar parte del mismo instrumento. Así, por ejemplo, en el numeral primero del artículo 12 se plantea que dicho intercambio puede suscitarse incluso cuando el material a proporcionar es confidencial, ${ }^{59}$ mientras que el numeral primero del artículo 28 maneja con mayor severidad el tema, ${ }^{60}$ aduciendo que no hay excepción respecto del uso de la información, pues siempre debe tener como límite el cumplimiento del fin para el cual fue recabada. ${ }^{61}$

Al realizar un análisis más completo de todos los elementos e intentando desglosar la contradicción nombrada, se entiende que actualmente la doctrina que había sido impuesta por el fallo Asociación Española de Banca Privada, ha sido retirada, desplazando a un segundo plano (Van Der Woude, 2004) ${ }^{62}$ el mecanismo de defensa que se había configurado en favor

58 Aunque meramente de carácter teórico, toda vez que el numeral primero del artículo 28 deja claro que las disposiciones en él incluidas, deben leerse y aplicarse "Sin perjuicio de los artículos 12 y 15(...)" (Comunidad Europea, 2003).

59 Lo cual se interpreta como el mecanismo elegido por el legislador europeo para apartar la rigidez que se había asentado en la UE al respecto tras el fallo Asociación Española de Banca, en razón del cual los bancos españoles vinculados con el caso adujeron que, a pesar de que el proceso era en aplicación de la normativa de competencia española, el Tribunal de defensa de la competencia español había utilizado la información que le había sido remitida por la Comisión, contenida en la notificación que los bancos habían presentado a esta última en búsqueda de que se les otorgara una exención. El Tribunal de Justicia Europeo dejó claro en su fallo, entre los apartados 29 al 43 y en el 48, que no estaba permitido -de acuerdo al Reglamento 17 (numeral segundo del artículo 20) - utilizar como prueba directa ese tipo de información, toda vez que en el asunto específico y en otros similares, se ponía en riesgo el secreto profesional, máxime cuando según su concepto los procedimientos comunitarios y los nacionales eran distintos, incluso aquellos referidos a la aplicación de los artículos 101 y 102 del Tratado.

60 El numeral primero de este artículo resulta ser una reproducción casi idéntica del numeral primero del artículo 20 del Reglamento 17/1962, ya que el cambio se ha restringido meramente a la configuración de palabras, que ha pasado de decir respecto del uso de la información que: "(...) no podrán ser utilizadas más que para el fin para el que hayan sido pedidas", a "(...) sólo podrá utilizarse para el fin para el que haya sido recabada." (Comunidad Europea, 2003).

61 Garantizando así que el uso de dicha información no estará dirigido a sustentar la aplicación de normas de protección al consumidor o normas afines de carácter nacional, que en razón de la cercanía teórica con las normas de competencia, en oportunidades son parte de las atribuciones de una misma autoridad nacional. Tal y como puede verse en Brammer (2009, p. 145), quien en la nota al pie de página número 174, ejemplifica dicha situación en los casos de Italia y Francia.

62 También los comentarios de aquellos que interpretan que en cualquier caso la doctrina de 
de las empresas, gracias a las conclusiones del Tribunal de Justicia en aquel caso, ${ }^{63}$ circunstancia que ha potenciado el intercambio y movimiento de la información, no de forma absoluta, sino controlada y en estricto cumplimiento de parámetros claros que ahora se encuentran mejor descritos en los instrumentos de relevancia. ${ }^{64}$

El mensaje principal que en la actualidad puede extraerse, tras la lectura de los instrumentos enunciados, es que las autoridades de competencia están obligadas a ser extremadamente cautelosas con el manejo del material que les es remitido, siempre en atención a los parámetros de los numerales segundo y tercero del artículo 12 del Reglamento. Dicha información debe usarse exclusivamente para cumplir el propósito para el cual fue recolectada, ${ }^{65}$ y como medio de prueba, sólo a efectos de la aplicación de los artículos 101 y 102 del Tratado.

Pudiendo eso sí, utilizar la información para aplicar el derecho nacional de la competencia, en los casos en los cuales sean aplicados de forma paralela al asunto tanto la normativa doméstica como el derecho de la competencia comunitario, y siempre y cuando de los resultados de ambas "aplicaciones" se obtuviese el mismo resultado (Reglamento 1/2003, 2003; Wish, 2008).

la sentencia Asociación Española de Banca Privada no eran operantes y eficientes para la consecución de los objetivos de la defensa de la competencia, toda vez que los estándares utilizados para fundamentar la decisión del Tribunal eran de muy alto rango, ya que ponían por encima principios del derecho tales como la protección de los derechos de defensa. (Reichelt, 2005, pp. 777 y ss).

63 Pues en la mencionada sentencia en ningún apartado se permitió a las autoridades de competencia darle un uso probatorio al material objeto de la transmisión, o incluso remitir información de carácter confidencial a otro Enforcement Body. Tal y como así lo pone de manifiesto Temple Lang (2000, pp. 15-18).

${ }^{64}$ Que en cualquier caso deben prevalecer y estar por encima de normas nacionales que quieran prohibir, impedir o trabar el intercambio de información entre autoridades participantes en la Red Europea de Autoridades de Competencia.

65 Que comúnmente guarda coherencia con el centro de la investigación, el cual se determina por la decisión u orden que ha dado la autoridad de competencia que obtuvo la información, al intentar comprobar hechos de los cuales presumía su acaecimiento. Aunque, igualmente, puede venir aparejado (el propósito) al expediente, sea cual sea la Autoridad de competencia que recolectó la información, ya que de la mano de la jurisprudencia, puede entenderse que los Enforcement Bodies tienen la obligación de dejar por escrito cuál es el propósito de la investigación y el eje central de la misma. Al respecto, Unión Europea, Tribunal de Justicia de la Unión Europea, Hoechst A. G. Vs. La Comisión, (21 Sept. 1989), apartados 41 y 42; Unión Europea, Tribunal de Primera Instancia, Limburgse Vinyl Maatschappij NVy Otros Vs. La Comisión de la Unión Europea, (20 Abril. 1999) y Dow Benelux NV Vs. La Comisión de la Unión Europea, asunto 85/87 (17 Oct. 1989). 
Al compendio de limitaciones al tránsito informativo hasta ahora enunciadas, se unen las del numeral tercero del artículo 12, en el cual el Reglamento deja claro que la información sólo podrá utilizarse como prueba para imponer sanciones a personas físicas, cuando se cumplan dos requisitos primordiales: que en las normas nacionales estén previstas dichas sanciones en relación con las infracciones a los artículos 101 y 102,66 y que la información haya sido recolectada respetando el nivel de protección del derecho de defensa de las personas físicas que en las normas nacionales se establezca, ${ }^{67}$ siendo requisitos estructurados para garantizar la protección efectiva y adecuada del individuo involucrado en un asunto de libre competencia. ${ }^{68}$

Así como el Reglamento 17/1962 daba una importancia destacada al secreto profesional en su relación con el tránsito informativo entre autoridades, ${ }^{69}$ el Reglamento 1/2003 en su artículo $28^{70}$ estableció un complemento al numeral segundo del artículo $12 \mathrm{del}$ mismo instrumento, ${ }^{71}$ erigiendo un límite más al mencionado tránsito, ampliando de forma explí-

66 Como se da en el Reino Unido, donde incluso se prevé una pena de prisión para las personas implicadas en un cartel, en infracción directa a los parámetros del Enterprise Act 2002 de 7 de Noviembre de 2002.

67 No pudiendo ser utilizada dicha información por la autoridad receptora de la información, para imponer penas privativas de la libertad. De acuerdo al numeral tercero del artículo 12 del Reglamento $1 / 2003$.

68 Por medio de la búsqueda de la consolidación de la analogía entre las distintas normativas nacionales al respecto, garantizando la equivalencia entre los derechos de defensa de los individuos, otorgados por los Estados entre los cuales está transitando la información, así como velando por la necesaria semejanza que debe existir entre las sanciones a imponer (Whish, 2008, p. 263). De forma genérica y acerca de los derechos involucrados de los individuos y empresas inmersas en el asunto, puede verse: Andreangeli, A. (2006), The Impact of the Modernisation Regulation on the guarantees of due process in competition proceedings. En European Law Review (3), (pp. 342 y ss).

69 En el numeral segundo del artículo 20, en el cual se leía: "Sin perjuicio de lo establecido en las disposiciones de los artículos 19 y 21, la Comisión y las autoridades competentes de los Estados miembros, así como sus funcionarios y otros agentes, estarán obligados a no divulgar las informaciones que hayan recogido en aplicación del presente Reglamento, las cuales, por su propia naturaleza, se hallan amparadas por el secreto profesional." (Consejo Europeo, 1962, art. 12) No siendo el único instrumento que lo desarrollaba, toda vez que el artículo 287 del Tratado igualmente lo planteaba imponiendo restricciones a la transmisión de cierta información, tal y como puede verse en el artículo 339 del Tratado de Funcionamiento de la Unión Europea actual.

70 Numeral segundo, desarrollado en su aplicación práctica en el literal (a) del apartado 28 de la Comunicación sobre cooperación en la red de autoridades de competencia (2004).

71 El cual es criticado por Van Der Woude (2004, p. 381), quien entiende que la mencionada regla es verdaderamente un obstáculo. 
cita las salvaguardas, protegiendo también los secretos profesionales (Soto Pineda, 2013a, pp. 186 y ss.) adheridos a la información transmitida por la Comisión o por las autoridades nacionales de competencia. ${ }^{72}$

De acuerdo con dichas reglas, hoy en día el Reglamento no desconoce en ningún momento que hay una obligación "tácita" de cooperación interinstitucional, pero a su vez entiende que la misma debe interpretarse a la luz de la protección de los secretos de negocios o profesionales de las empresas, ${ }^{73}$ generando que las autoridades estén obligadas a no divulgar la información que esté amparada por el secreto profesional y que sólo deban revelar dicho material, facilitándoselo a otras autoridades, en circunstancias excepcionales $^{74}$ que no posibiliten su utilización por parte de la autoridad receptora, más allá del objetivo por el cual fue recolectada. ${ }^{75}$

Del mismo modo, dentro de los límites al uso de la información, es importante manifestar que buscando una protección más certera del material transmitido, la Comunicación sobre la Red, además de desarrollar aspectos genéricos incluidos en el Reglamento, planteó parámetros a seguir para solucionar una circunstancia tan susceptible como la del uso y "cesión" de

72 El objetivo del Reglamento 1/2003 en lo referente al secreto profesional no es tanto regular las relaciones entre los distintos Enforcement Bodies, sino otorgar las herramientas legales suficientes para "administrar" correctamente las solicitudes que las mismas empresas involucradas, así como los interesados (competidores, clientes y demás), puedan realizar para acceder a la información transmitida por otra Autoridad; También para garantizar que la información amparada por el secreto profesional no será revelada una vez entre a formar parte de la base de datos de la Red Europea de Autoridades de Competencia (Brammer, 2009, p. 147).

73 En relación con este tema: Unión Europea. Tribunal de Justicia de la Unión Europea, Sentencia asunto 85/76 Hoffmann-La Roche E Co. AG Vs. La Comisión de la Unión Europea, apartado 13, (13 feb. 1979). Texto disponible en http://eur-lex.europa.eu/LexUriServ/LexUriServ.do?uri=CE LEX:61976CJ0085:ES:PDF; Unión Europea, Tribunal de Justicia de la Unión Europea, Sentencia asunto C-62/86 AKZO Chemie BV Vs La Comisión de la Unión Europea, apartado 28 (3 Jul. 1991); Unión Europea, Tribual de Justicia de la Unión Europea, Sentencia asunto C-36/92 PXX/XX SEP Vs. La Comisión, apartado 36, (19 May. 1994).

74 Como aquella en virtud de la cual la Comisión debe facilitar a las autoridades nacionales de competencia la información de mayor relevancia.

75 Asociación Española de Banca Privada, apartados 21, 37 y 42; así como también el asunto SEP Vs. La Comisión, apartados 27 y 28. Siendo a su vez relevante el aporte realizado por la sentencia del Tribunal de Primera Instancia (sala primera ampliada), de 20 de febrero de 2001, MannesmannröhrenWerke AG Vs. La Comisión de la Unión Europea, asunto T-112/98, en sus apartados 85, 86 y 87, donde el Tribunal deja claro que resulta muy complejo para las autoridades inducirse amnesia, para olvidar aquello que han visto, gracias a la información proporcionada. Por lo que si bien tienen una obligación de darle un uso equivalente al de origen, a su vez nadie puede impedir que dicho material sea analizado como relevante al interior de la Autoridad para iniciar algún procedimiento o una investigación en búsqueda de algunos hechos que efectivamente, conocen, han acaecido. 
la información obtenida como resultado de un programa de clemencia. Siendo lo más esencial, consolidar el amparo de aquellos que se acogen a este tipo de programas, garantizando que serán seguidos ciertos lineamientos para el manejo del material proporcionado por aquellos, y que se evitará comprometer su posición, ${ }^{76}$ a saber:

- Impidiendo a las autoridades nacionales iniciar procedimientos en virtud de la información facilitada a la Red por una autoridad que acogió en un programa de clemencia a una empresa, individuo, etc. ${ }^{77}$ y/o

- Requiriendo el consentimiento del solicitante de clemencia, quien proporciona la información, para transmitir la misma a otro Enforcement Body, salvo en los supuestos previstos en el apartado 41 de la Comunicación sobre la Red. ${ }^{78}$

A manera de conclusión acerca del tránsito informativo y los límites expuestos, podría decirse que a pesar de existir referencias y "restricciones" en el ejercicio de las atribuciones de los Enforcement Bodies al interior de la Red europea de autoridades de Competencia, las cuales pueden a su vez condicionar la labor de defensa de la competencia llevada a cabo por aquellas, la realidad es que la remisión de información y la unificación del material relevante que le permita conocer del asunto particular a todos los partícipes, es uno de los puntos esenciales del paquete de moderniza-

76 Acerca de esta eventualidad, consultar: Mataija, M. (2010), The European competition Network and the Shaping of EU competition policy, en Croatian Yearbook of European Law and Policy, 6 (pp. 89-90).

77 Teniendo - de acuerdo al apartado 39 de la Comunicación sobre cooperación en la Red de Autoridades de Competencia (2003) - la posibilidad de iniciar un procedimiento respecto de unos mismos hechos, en los casos en los cuales la investigación se base en información proporcionada por otras fuentes o cuando se cumpla alguno de los parámetros del apartado 41 de la misma Comunicación. Circunstancia que es criticada con ahínco por varios sectores de la doctrina, toda vez que resulta incongruente que no haya una compenetración en el tema sancionatorio de todos los programas de clemencia dentro de la UE y que se traslade a las empresas que desean cooperar con las autoridades administrativas, el esfuerzo de acogerse simultáneamente a todos los programas de clemencia existentes en la UE si quieren asegurarse la "indulgencia" en cada uno de los territorios afectados por su transgresión. (Furse, 2006; Korah, 2007).

78 Acerca de los límites planteados por la Comunicación sobre cooperación en la Red de Autoridades de Competencia con respecto a los programas de clemencia, consultar los apartados 37 al 42 de dicho instrumento y la Comunicación de clemencia 2006, así como los comentarios que se encuentran en Soto Pineda, J. (2010) Aproximación a la implementación de los programas de clemencia como instrumentos del derecho de la competencia, (Con)Textos, (3), pp. 167-172. 
ción del año 2003, ya que se le otorga un papel protagónico tanto en el Reglamento 1/2003, como en la Comunicación sobre la Red, que a la larga logra implicar en mayor medida a las autoridades, quienes, a pesar de no tener una obligación de cooperación de carácter taxativo plasmada en el texto jurídico, sí se encuentran ahora mejor empoderadas para, superada la doctrina Asociación Española de Banca Privada, transmitir la información y esperar un tratamiento similar por parte de los demás Enforcement Bodies. ${ }^{79}$

\subsubsection{Asistencia administrativa en las labores de investigación}

Como resultado de las importantes variaciones que ha traído aparejadas la reforma del año 2003 al completo, y en específico -como instrumento principal- el Reglamento 1, ahora las autoridades nacionales de competencia, en razón de la obligación a su cargo de aplicación de los artículos 101 y 102 del Tratado, deben enfrentarse a casos particulares susceptibles de tener efectos en más de uno de los Estados miembros (European Competition Network, 2010). En virtud de la estructura económica comunitaria de carácter supranacional, el alcance frontal o transversal de las infracciones a las normas de libre competencia es ahora mayor, haciendo más compleja la tarea de los Enforcement Bodies. ${ }^{80}$

En ese sentido, es menester que las autoridades nacionales hagan todo lo posible por contar con la información necesaria para delimitar los efectos de la conducta en otros Estados miembros. Así, deben recolectar todo el material posible, incluso aquel que por su naturaleza y particularidades no pueda ser hallado en su propio Estado, sino en el de otro territorio de la UE, o bien porque el emplazamiento empresarial donde se presume consignada dicha información está en un Estado foráneo, o simplemente porque las circunstancias particulares del asunto así lo hacen necesario.

Con antelación a la aparición del Reglamento 1/2003 la situación de las autoridades nacionales de competencia al respecto no era ni mucho menos ilusionante, ya que el acceso a la información, la evaluación y la

79 Pone de manifiesto el margen de mejora (Gerard, 2013, pp. 26 y ss.).

80 Los efectos de las conductas restrictivas se extienden, gracias al panorama de inversión y mercado supranacional, cada vez más globalizado a muchos países, Estados y territorios que en principio no deberían verse impactados (Alonso Soto, 2001; Mataija, 2010). 
utilización de la misma en el marco de un proceso distaban de ejercerse con facilidad, a lo que es necesario añadir que no era tomada en cuenta de forma adecuada la disposición de la información para delimitar la autoridad mejor situada para hacerse cargo de un asunto.

El numeral primero del artículo 22 del Reglamento $1 / 2003^{81}$ vino a solucionar dichos inconvenientes, dejando claro que las autoridades nacionales tienen la posibilidad de llevar a cabo investigaciones en el territorio de otro Estado miembro, actuando a través de la autoridad de competencia de este último. De esta manera, adquiere la posibilidad de dirigir las labores que son realizadas por una autoridad análoga (Pace, 2007). ${ }^{82}$

El artículo mencionado, además de incluir esa posibilidad en su texto, tuvo inmenso cuidado en la labor de reconciliación de dos aspectos que a simple vista pueden chocar como resultado de dicho poder ahora conferido a las autoridades nacionales, pues el ejercicio "coercitivo" de los poderes en cabeza de cada autoridad en un territorio específico asignado es susceptible de colisionar con el objetivo de proporcionar los medios que sean necesarios, para hacer frente de forma efectiva y diligente a la infracción que está teniendo efectos en más de un Estado miembro.

El objetivo claro de la reforma del año 2003 -que a la larga ha demostrado ser idónea para darle respuesta a las necesidades del sistema (Cengiz, 2010) - fue el de potenciar la actuación en conjunto y consolidar la cooperación entre autoridades también en la materialización de diligencias, ya que en la UE se es cada vez más consciente de la imposibilidad que tiene un solo Estado para hacer frente a las múltiples maniobras de las empresas -cada vez más poderosas e influyentes (Hovenkamp, 2003; Pastor, 2005)-, los mercados, etc.

81 El cual se transcribe por ser guía del desarrollo que en el presente apartado se hará sobre la asistencia administrativa en él plasmada: "Una autoridad de competencia de un Estado miembro podrá proceder en su territorio a realizar cualquier inspección u otra medida de investigación de los hechos al amparo de su derecho nacional en nombre y por cuenta de la autoridad de competencia de otro Estado miembro, con el fin de demostrar la existencia de una infracción del artículo 81 o del artículo 82 del Tratado. Cualquier intercambio y utilización de la información recopilada se llevará a cabo en aplicación del artículo 12". Solución parcial del inconveniente de acuerdo a los conceptos de Gerard (2013, p. 31).

82 Pace (2007) resalta el comunicado de prensa del 15 de Julio de 2004 en el cual la Autoridad de competencia Italiana en el asunto referente a los fabricantes de leche infantil, dejó claro que su labor de protección también se favorecía gracias a la cooperación que otras autoridades nacionales de competencia otorgaban, por lo que investigaciones simultáneas en las cuales se llevaran a cabo diligencias en emplazamientos empresariales fuera de Italia, ahora estaban más que sustentadas. 
A pesar de ser un avance significativo que facilita llevar las infracciones a las normas de libre competencia a su fin, sorprende que las condiciones en las cuales dicha posibilidad debe ser ejercida no estén detalladas ni en el Reglamento, ni en la Comunicación sobre la Red. Los instrumentos enunciados se han limitado a exponer que dicha posibilidad cooperativa existe, pero sin extenderse en ciertas reglas básicas que serían de gran utilidad para hacer más fluido el mecanismo de cooperación y evitar inconvenientes que en todos los casos de combinación de facultades son susceptibles de presentarse.

En todo caso, del artículo 22 del Reglamento y de los apartados 29 y 30 de la Comunicación sobre la Red, se extrae que el aspecto esencial para el legislador europeo, en lo referido a este significativo asunto, ha sido el de dejar claro cuál es el manejo que debe darse a la información recolectada por la Autoridad que efectivamente lleva a cabo la diligencia tras la solicitud extendida por parte de otra.

La conclusión al respecto tras la lectura de la oración final del numeral primero del artículo 22 del Reglamento, es que la información recolectada en virtud de este mecanismo de cooperación debe ser trasladada y utilizada de acuerdo a las condiciones del artículo 12 del mismo Reglamento, ${ }^{83}$ restándole importancia a conocer si la autoridad poseedora de la información la tenía en su poder con antelación a la solicitud extendida por la autoridad homóloga, o si la obtuvo en una diligencia solicitada por esta última.

Si bien los instrumentos comunitarios solo hablan de transmisión de la información fruto de la solicitud en lo referido a las particularidades para el ejercicio de este mecanismo de cooperación, la doctrina ha coincidido al exponer los aspectos a los que las autoridades vinculadas (requirente y requerida) deben prestar especial atención para poder llevar a buen puerto las atribuciones investigadoras "conjuntas". ${ }^{84}$ En virtud de aquellos aportes, ha quedado claro que las condiciones en las cuales la colaboración se pondrá en marcha, se infieren, toda vez que en el derecho interno del Estado

83 El cual fue objeto del desarrollo en el presente trabajo en los apartados referentes al intercambio de información, tanto vertical como horizontal, así como en lo expuesto acerca de los límites a dicho instrumento cooperativo.

84 El más especial de los desarrollos al respecto, bajo el epígrafe "Five Umwritten Basic Safeguards" puede encontrarse en Brammer, S. (2009), Co-operation Between National Competition agencies in the enforcement of EC Competition Law, (pp. 286-290), Oxford \& Portland, Hart Publishing. 
al cual pertenece la autoridad receptora de la solicitud, están plasmados los parámetros que aquella debe seguir para realizar las diligencias y para ejercer sus poderes de investigación. ${ }^{85}$

Por consiguiente, la doctrina ha resaltado que es fundamental que la autoridad requirente proporcione a la autoridad requerida toda la información necesaria en la cual basa sus sospechas. Para realizar la diligencia, la autoridad del Estado que efectivamente la llevará a cabo necesita un nivel mínimo de certeza acerca de la probabilidad de la infracción, basado en indicios, denuncias o similares, que puedan encuadrarse en los patrones estándar aplicables en el Estado miembro donde se llevará a cabo la diligencia. Con dicho material estará más sustentada la causa de la investigación, y podrá establecerse con mayor facilidad la conveniencia de realizar una inspección en un local empresarial o comercial, realizarla en un emplazamiento privado, etc. ${ }^{86}$

Así mismo, la doctrina ha resaltado que la autoridad requerida deberá hacer frente a la solicitud de asistencia, siempre según los parámetros que estén previstos en las normas de su Estado para ejercitar su atribución investigadora, dependiendo de la normativa nacional, la delimitación de las condiciones en las cuales la información será recolectada, ${ }^{87}$ y de si, efectivamente, la autoridad requerida tiene el poder, en términos de proporcionalidad de las medidas, para llevar a cabo ciertas diligencias ${ }^{88}$ que le han sido encomendadas. ${ }^{89}$

85 Como así puede verse en, Unión Europea, Tribunal de Justicia de la Unión Europea, Roquette Frères, asunto C-94/00, (22 Oct. 2002), apartados 34 y 35; así como también Unión Europea, Tribunal de Justicia de la Unión Europea, Hoechst A. G. Vs. La Comisión), asuntos acumulados 46/87 y 227/88, (21 Sept. 1989), apartados 33 y 34.

86 Acerca de las mencionadas diligencias, consultar: Soto Pineda, J., (2013a), A propósito de un elemento esencial de la defensa de la competencia en Europa: las facultades de investigación de la Comisión en materia de inspección, Revista de Ciencias jurídicas y sociales, Foro nueva época, 16(1), (pp. 168-186).

87 Por ejemplo requiriendo o no la colaboración de un Juez, en la obtención de una orden judicial que permita al Enforcement Body de carácter administrativo llevar a cabo la diligencia.

88 Como por ejemplo aquella que más debate ha generado una vez adherida en el paquete de modernización, en virtud de la cual se inspecciona un emplazamiento privado, donde se presume, será encontrada la información relevante que permitirá descubrir la transgresión.

89 Además, claro está, de las particularidades específicas que en cada derecho interno sean desarrolladas para ejercer el poder de investigación, pues, si bien en la normativa nacional de los Estados miembros no se pueden incluir trabas que impidan cumplir los objetivos de los Tratados de la Unión y de los instrumentos legales puestos a disposición en la UE, sí que se otorga una Au- 
Que se deje en manos de las normativas nacionales la estructuración de ciertas condiciones específicas en las cuales efectivamente se suscitará la asistencia administrativa en la investigación entre autoridades nacionales, puede ser interpretado por muchos como un acierto, ya que en los instrumentos internos se otorgan las suficientes herramientas para llevar a buen puerto las pesquisas. No obstante, algunos pensamos distinto, ya que interpretamos que aquella "licencia" es un desacierto que debería ser remediado, puesto que con el procedimiento actual pueden producirse inconvenientes para los cuales no existen soluciones, como por ejemplo para solventar que en el curso de la investigación se hayan cometido irregularidades en la recolección de información y dicho material ya se hubiese remitido a la Autoridad requirente, siendo, en cualquier caso, una circunstancia desafortunada que aunque hipotética, no se interpreta lejana. ${ }^{90}$

En las mismas condiciones que la transmisión de información horizontal, este instrumento de cooperación no se configura en términos imperativos para las autoridades nacionales de competencia, ya que ningún precepto comunitario obliga a aquellas a responder afirmativamente una solicitud de asistencia realizada por una autoridad par, $^{91}$ por lo que es un tema netamente discrecional en virtud del cual ningún Enforcement Body de carácter nacional debe entender garantizada la asistencia requerida, ya que así como existe la posibilidad de que se responda afirmativamente la solicitud de colaboración en las labores de investigación, puede darse la eventualidad de que sea declinada la misma. ${ }^{92}$

tonomía suficiente para estructurar condiciones específicas que se amolden a la cultura jurídica de aquel territorio.

90 Entienden que esta circunstancia puede llegar a presentarse, Van Gerven (2006) y Gauer (2005), quienes coinciden al expresar que de haberse recolectado la información en claro incumplimiento de las normas procesales que le regulan en el Estado de origen donde se efectuó la diligencia, la Autoridad receptora, debe en todos los casos abstenerse de usarla, pues la ilegalidad de los aspectos de investigación siempre desemboca en la inutilidad del material probatorio, ya que no podrá ser utilizado por otros Enforcement Bodies. Este argumento es complementado por Dekeyser y Dalheimer (2005), quienes entienden que la información recolectada ilegalmente debe ser apartada del análisis del asunto, destruida por el receptor o retornada a quien la remitió, y notificada su extracción del caso, a los interesados.

91 Aunque para algún sector, que se decline dicha asistencia, en todo caso debe estar sujeto al deber de cooperación entre Estados y autoridades de dichos Estados en los Tratados (Van Gerven, 2006, p. 339).

92 Aunque eso sí, debe hacerse una salvedad de importancia, ya que de accederse a prestar asistencia administrativa en la investigación, la Autoridad Nacional de competencia del territorio donde se llevase a cabo la diligencia que permitiese la recolección del material probatorio, estará 
1.2.3. Armonización de competencias entre Enforcement Bodies: rechazo, suspensión y terminación de procedimientos

Como ha sido manifestado previamente, con los cambios surgidos tras el año 2003, se ha intentado potenciar la coherencia de la defensa de la competencia en la UE, por medio de la disposición de ciertas herramientas que garantizan un ejercicio más eficaz de las atribuciones de los Enforcement Bodies, a la vez que limitan y disciplinan las posibles pugnas que pueden generarse entre las autoridades integrantes de la Red en razón de la pluralidad de elementos a conciliar (Guillén Camarés, 2013 y Gerard, 2013).

De tal manera, el artículo 13 del Reglamento 1/2003 proporciona herramientas de cooperación anexas que se unen a aquellas descritas en los apartados anteriores. Gracias a estos instrumentos de armonización de competencias, la Comisión, como principal Autoridad Comunitaria de competencia, se encuentra en mejor posición para garantizarse que cualquier asunto que involucre la aplicación de la normativa de libre competencia, será conducido de forma exclusiva por sólo una de las autoridades capacitadas para ello. ${ }^{93}$

Concretamente, el artículo 13 deja claro que es motivo suficiente para desestimar una denuncia, para suspender un procedimiento propio o para cerrar un expediente sobre un asunto específico, el hecho de que otra autoridad esté involucrada con la resolución de un caso. A saber, en dos diversas circunstancias, como lo son: (i) que otro Enforcement Body se haya hecho cargo del asunto en el pasado o (ii) que se esté encargando del asunto en el preciso momento en el cual se encuentra también en manos de una segunda autoridad.

Si bien la cultura dinámica de la UE puede suscitar cambios en las situaciones puntuales, que hacen necesaria la puesta en marcha de aquellas soluciones adheridas al artículo 13, cabe resaltar que de momento, las circunstancias más recurrentes que las originan son:

obligada a remitirlo a la Autoridad solicitante, no pudiendo a su vez, prestar la asistencia en la materialización de diligencias y negarse a proporcionarla cuando le es requerida (Reichelt, 2005).

93 Sobre los mencionados instrumentos, consultar: Geradin, D., Reysen, M., \& Henry, D. (2008), Extraterritoriality, Comity and cooperation in the EC Competition Law, en Documento de trabajo, (pp. 7-11). 
- Aquellas en las cuales más de una autoridad ha recibido la misma denuncia.

- Aquellas en las que más de una autoridad ha tomado la decisión de actuar de oficio en razón de un mismo asunto.

- Aquellas en las cuales se presenta una denuncia ante la Comisión cuando una autoridad administrativa nacional de competencia ya se ha hecho cargo del asunto particular. ${ }^{94}$

Los paralelismos entre procesos son fuente primaria de la puesta en marcha de los mecanismos proporcionados por el artículo 13, y a pesar de que puedan a simple vista interpretarse como inusuales, en la realidad no son una eventualidad extraña, ya que favorecidos por las condiciones mismas del sistema, pueden incluso llegar a ser comunes entre las autoridades nacionales, y solo entre ellas, toda vez que la Comisión como autoridad privilegiada y superior, se excluye de dicha posibilidad (Komninos, 2007; Paulis, 2001; Nazzini, 2004; Nazzini, Renato \& Andenas, 2006), ya que cuenta con el poder para desplazar a otros Enforcement Bodies del conocimiento de un asunto particular cuando así lo estime pertinente..$^{95}$

No obstante dicha superioridad, la Comisión cuenta también con la posibilidad de poner en marcha los instrumentos de coordinación del artículo 13, por ejemplo desestimando una denuncia, en aquellos casos en los cuales tenga conocimiento de que el mismo asunto está siendo tramitado por una autoridad nacional.

En cualquier caso, el matiz entre el rechazo a una denuncia por parte de la máxima autoridad comunitaria y aquel efectuado por una autoridad nacional, está en los motivos que impulsan a cada uno de aquellos Enforcers a tomar la decisión. De este modo, normalmente la Comisión Europea basa su rechazo en el poco interés comunitario acerca de un asunto,

94 Este compendio de circunstancias son enunciadas por Pace (2007), quien interpreta este instrumento de cooperación como la segunda respuesta a los conflictos que son susceptibles de generarse cuando más de una autoridad se rodea de las circunstancias propias de un asunto particular, ya que, según su óptica, en un marco temporal coherente y común, siempre debe venir la información circundante entre los miembros de la Red europea de autoridades de competencia.

95 En razón del texto consignado en el numeral sexto del artículo 11 del Reglamento en desarrollo, donde queda claro que no es posible que se den procesos paralelos entre la Comisión y una Autoridad Nacional de Competencia en aplicación de los artículos 101 y 102 del Tratado de Funcionamiento de la Unión Europea. 
en su deseo por reducir la carga de trabajo al interior de sí misma o en las condiciones mismas del caso; ${ }^{96}$ mientras que las autoridades nacionales lo que buscan es concentrar en una sola autoridad de carácter nacional el conocimiento sobre un asunto particular sin que se solapen procesos en torno a un mismo supuesto.

Es claro que lo esencial es -sea cual sea la autoridad que en potencia esté capacitada para suspender, rechazar o terminar un proceso a su cargo- que la información fluya oportunamente entre los diversos miembros de la Red Europea de Autoridades de Competencia, donde se encuentran estructuradas las bases principales del tránsito que permite a los diversos Enforcers sustentar las decisiones que toman en virtud del artículo 13.

$Y$ es que, de conformidad con el numeral tercero del artículo 11 del Reglamento, es menester que sea remitida a la Comisión, por parte de las autoridades administrativas nacionales, información sobre un asunto particular antes de realizar las primeras diligencias formales de investigación o inmediatamente después de iniciadas.

Debido a ello, no cabe duda de que es la Comisión quien tiene la obligación de garantizar una comunicación persistente e ininterrumpida al interior de la Red, dándole rotación entre los diversos Enforcers a la información recibida, para que así aquellos, con conocimiento suficiente sobre el asunto, puedan reaccionar a tiempo, bien suspendiendo un proceso del que venían conociendo, rechazando una denuncia acerca de un asunto específico, remitiendo la toma de decisión a otra autoridad, etc.

A la par de la obligación informativa descrita, es importante resaltar que este tipo de mecanismos no sólo se suscitan en aquellas situaciones en las cuales una autoridad nacional rechaza una denuncia sin haber realizado actuación alguna, pues pueden darse incluso situaciones especiales en virtud de las cuales una autoridad nacional decida cerrar el expediente de un asunto, muy a pesar de haber logrado avances respecto del mismo, llevando a cabo diligencias, notificaciones o similares.

Si bien en principio aquello puede interpretarse como un contrasentido, toda vez que, al haberse hecho avances en la resolución de una cuestión

96 De acuerdo, con el apartado 41 de la Comunicación de la Comisión sobre la tramitación de denuncias por parte de la Comisión al amparo de los artículos 81 y 82 del Tratado CE, de 27 de Abril de 2004, así como también al numeral tercero del artículo 7 del Reglamento 773/2004, relativo al desarrollo de los procedimientos de la Comisión con arreglo a los artículos 81 y 82 del Tratado CE. 
particular, se presume que la autoridad que han alcanzado aquellos logros es la mejor posicionada para "rematar" el caso, la realidad es que puede existir la eventualidad de que otro Enforcement Body de carácter nacional sea designado para concluir con la causa sin que aquello tenga un impacto negativo en las investigaciones efectuadas. Por lo que ante dicha contingencia, es necesario que -como efectivamente se está suscitando en el terreno práctico- se vean reforzados los canales de información y se garantice un uso y una relevancia al material recolectado por otra $\mathrm{u}$ otras autoridades (Kekelekis, 2009), que favorezca la incursión en el procedimiento definitivo, le añada valor al mismo ${ }^{97}$ y a su vez prevenga que dicha información sea descuidada u olvidada.

Además de las particularidades de los instrumentos dispuestos para evitar contradicciones fruto del posible paralelismo de procesos, el numeral segundo del artículo 13 del Reglamento en desarrollo también proporciona respuesta a las situaciones en las cuales el asunto objeto de un proceso ya haya sido tratado por otra autoridad de competencia; otorgando así la posibilidad a los distintos Enforcement Bodies de evitar contradicciones innecesarias con los pronunciamientos de otras autoridades, dándoles el poder de rechazar las denuncias que se encuadren en dicha situación. ${ }^{98}$

Así mismo, como la parte final del artículo 5 del Reglamento da la posibilidad a las autoridades nacionales de competencia decidir que no procede la intervención en virtud de un supuesto hecho particular, el artículo 13 les otorga la posibilidad de esquivar posibles contradicciones, permitiéndoles cerrar un caso con base en el presunto choque que puede presentarse con otra autoridad, incluso sin considerar los méritos del asunto, no teniendo la obligación de explicar las razones puntuales en las cuales ha basado su decisión, tal y como puede verse en el apartado 22 de la Comunicación sobre la Red. ${ }^{99}$

97 El artículo 12 del Reglamento favorece dicha situación, toda vez que ahora las autoridades nacionales tienen la posibilidad de centralizar con más facilidad los esfuerzos, pudiendo incluso dar apertura a procedimientos referentes a asuntos con los que en un escenario distinto, nunca se enfrentarían.

98 Sin importar cuáles fueron las particularidades explícitas de la decisión tomada por una $\mathrm{Au}^{-}$ toridad Nacional de Competencia, pues según la opinión de Brammer "(. . ) It is irrelevant, in this respect, wheter the other NCA has adopted a negative decision or equally rejected the complaint" (2009, p. 69).

99 En el cual queda claro que está dentro de las atribuciones de estas el poder de tomar la decisión acerca de la suspensión o cierre de un proceso; toda vez que gracias a dicha posibilidad 
Que dicha realidad esté planteada en los mencionados términos, ${ }^{100}$ en ningún caso puede ser interpretado como un consentimiento tácito a la impunidad, o como una atribución desfavorecedora de los intereses de los perjudicados. A pesar de que efectivamente las autoridades de competencia puedan decidir no intervenir en ciertas circunstancias como las enunciadas, la realidad es que en todos aquellos casos en los cuales exista evidencia que compruebe la infracción de las normas de libre competencia comunitarias, por lo menos una de las autoridades administrativas nacionales o la Comisión, si hay interés comunitario, deberá hacerse cargo de la investigación.

A manera de conclusión, una vez expuestas todas las particularidades acerca de este instrumento de cooperación, solo puede resaltarse la idoneidad para evitar confrontaciones y la necesaria compenetración informativa en tiempo real entre las autoridades de las cuales requiere, pues de carecer de dichas atribuciones, su efectividad sería nula, ya que, si bien la multiplicidad de procesos paralelos sobre un mismo asunto puede enriquecer su resolución una vez la información se centraliza en la autoridad final, lo cierto es que cada procedimiento puede suscitar contradicciones, por lo que resulta ser un instrumento dependiente del tránsito informativo, puesto que no puede gestionarse por sí solo sino gracias al cumplimiento que los distintos Enforcement Bodies le den al artículo 12 del Reglamento y a sus instrumentos complementarios. ${ }^{101}$

se garantiza la coherencia en la aplicación de la normativa de libre competencia, de acuerdo a las condiciones específicas del asunto y al interés que se le haya atribuido al interior del Enforcement Body al caso particular.

100 Por ambos numerales del artículo 13, en razón de los cuales, no puede olvidarse quedan de lado las normas nacionales que impongan una obligación a sus autoridades nacionales, de evaluar el asunto a pesar de que esté siendo objeto de un procedimiento llevado por otra Autoridad de Competencia, o ya haya sido resuelto por otro Enforcement Body de carácter nacional. Existiendo una contradicción con dicho principio en los derechos belga y francés, donde se imponen trabas a dicha posibilidad de las autoridades de competencia de aquellos Estados, pues en el primero se exigen en todos los casos resoluciones razonadas y formales, así como en el segundo, donde, además, dichas resoluciones deben someterse a una revisión de carácter judicial (Idot, 2004).

${ }_{101}$ De esta idea es igualmente Pace (2007), quien incluso crea una línea temporal en la que siempre, de configurarse el tránsito informativo, se podrá acceder a los instrumentos de cooperación descritos en este apartado. 


\section{Conclusiones}

La Red Europea de Autoridades de Competencia configura una de las más grandes iniciativas alrededor del globo para proteger la estabilidad del ecosistema competitivo. Como foro de cooperación y colaboración en materia de libre competencia, es el ejemplo primordial en cualquier iniciativa internacional que se emprenda fuera de la UE, pues, en virtud de ella, se ha incrementado exponencialmente el compromiso de protección conjunta de los mercados emprendido por las autoridades administrativas de competencia.

No obstante sus virtudes, de la presente investigación se extrae que ciertos inconvenientes relacionados con la intención cooperativa coartan al día de hoy la fluidez de la aplicación pública de las normas de libre competencia europeas. Así, por ejemplo, resulta cuestionable que en los instrumentos de relevancia, y en el Reglamento 1/2003 especialmente, no estén suficientemente claras ciertas condiciones fundamentales que requiere el sistema al completo. Carencias que pueden ser resumidas en:

- La definición insuficiente del funcionamiento del reparto de asuntos que giran en torno a las normas de libre competencia.

- El planteamiento desigual de obligaciones de cooperación y armonización de competencias a cumplir por parte de las autoridades nacionales de competencia o por parte de la Comisión Europea.

- La disposición de un sistema discrecional de cooperación en el cual las autoridades del mismo nivel no se encuentran obligadas a notificarse el inicio de procedimientos o la toma de decisiones.

- El silencio acerca de los procedimientos a seguir por parte de las autoridades nacionales para consolidar la cooperación interinstitucional.

- El ejercicio exiguo de una salvaguarda del principio de Non Bis In Idem en materia de libre competencia.

- La protección indiferente de la información aportada por empresas y personas que se acogen a programas de clemencia en cualquier emplazamiento comunitario.

El paquete de modernización del año 2003 dejó varios aspectos a la deriva que a pesar de su profundidad no han impedido que la Red 
Europea de Autoridades de Competencia se consolide año tras año en su tarea cooperativa. En el sistema se han presentado colisiones de importancia que siempre han sido solucionadas al interior del foro. Y muy a pesar de que pueda interpretarse que de forma natural y sin intervención, gracias a los precedentes, los problemas se irán solventado con el pasar de los años, la realidad es que hasta tanto no sea potenciado un equilibrio alrededor de todos los conceptos reseñados, la Red no alcanzará sus mejores cuotas.

Parece extraerse de la experiencia generada por la Red y por las modificaciones del 2003, que el objetivo que se ha mantenido inalterable durante 10 años, ha sido el de consolidar un sistema no en la imperatividad, sino en la discrecionalidad y en el trabajo conjunto concertado. Intención loable que, gracias al ejercicio riguroso del derecho y al interés europeo defendido por la mayoría de Estados, ha sido transpuesta parcialmente, toda vez que en oportunidades las autoridades -con diversos intereseshan aprovechado los vacíos mencionados para atascar procedimientos de libre competencia.

Perfeccionar los propósitos del paquete de modernización del año 2003 para que este tipo de posibilidades dejen de presentarse, es posible gracias a la extensión de los instrumentos jurídicos comunitarios. Por lo que proceder a aquella enmienda se interpreta imperativo. Como también que sea conciliada la participación de los jueces nacionales en una Red supranacional de autoridades de competencia, pues hasta tanto aquello no suceda, el sistema al completo puede seguir presentando inconsistencias riesgosas para la idea comunitaria.

Al margen de inconvenientes, ninguna red de autoridades de competencia alrededor del globo está estructurada con el nivel de detalle que la europea, razón por la cual la experiencia comunitaria se hace más valiosa, ya que con ella las iniciativas de la OECD y la Red Internacional de competencia pueden verse potenciadas. La determinación taxativa de las condiciones de la colaboración es esencial en cualquier proceso de conjunción de competencias, por lo que encontrar el soporte jurídico que dará lugar a aquellas iniciativas, debería ser en este momento una de las prioridades de la defensa de la competencia internacional. 


\section{Referencias}

Alonso Soto, R. (2001). Competencia y comercio. El marco general. En I. Blásquez Navarro, C. Esposito Maccissi, \& A. Remiro Brotons (Eds.), La Organización Mundial del Comercio y el regionalismo europeo.Madrid: Dykinson.

Andreangeli, A. (2006). The Impact of the Modernisation Regulation on the guarantees of due process in competition proceedings. European Law Review. (3), pp. 342-363.

Arias Esteban, I. (2011). Aspectos a considerar para un efectivo intercambio de información tributaria, Manual CIAT para la Implementación y Práctica del Intercambio de Información para Fines Tributarios. (159), pp. 1-9.

Bellamy, C. \& Child, G. (1996) Common Market Law of Competition, Londres: Sweet \& Maxwell.

Borchardt, K.D. (2000). El ABC del Derecho Comunitario, Bruselas: Oficina de publicaciones oficiales de las Comunidades Europeas.

Brammer, S. (2009). Co-operation Between National Competition agencies in the enforcement of EC Competition Law, Oxford y Portland: Hart Publishing.

Buccirossi, P., Ciari, L., Duso, T., Spagnolo, G., \& Vitale, C. (2011) Measuring the Deterrence Properties of Competition Policy: The Competition Policy Indexes. Journal of Competition Law \& Economics, 7(1), pp. 165-204.

Burnside, A., \& Crossley, H. (2004). Cooperative mechanisms within the EU: a blueprint for the future cooperation at the international level, International Trade Law \& Regulation, (10), pp. 25-35.

CEE Comunicación de la Comisión relativa a la cooperación entre la Comisión y las autoridades de competencia de los Estados miembros para el tratamiento de determinados asuntos incluidos en los artículos 81 y 82del Tratado CE, Diario Oficial de la UE, DOCE 97/C 313/03 de 15 de octubre de 1997.

CEE Comunicación de la Comisión sobre la cooperación en la red de autoridades de competencia. Diario Oficial de la UE, DOCE C 001 de 27 de abril de 2004.

CEE Comunicación de la Comisión sobre la tramitación de denuncias por parte de la Comisión al amparo de los artículos 81 y 82 del Tratado CE, de 27 de Abril de 2004, Diario Oficial de la UE, DOCE C 001 de 27 de abril de 2004.

CEE Paquete de modernización del Sistema Comunitario de defensa de la competencia: Comunicaciones y directrices fechadas el día 27 de Abril de 2004, publicadas en el Diario Oficial de la Unión Europea C 101/05. La Comunicación de la Comisión sobre la cooperación en la Red de autoridades de competencia (pág. 43), la Comunicación de la Comisión relativa a la cooperación entre la Comisión 
y los órganos jurisdiccionales de los Estados miembros de la Unión Europea para la aplicación de los artículos 81 y 82 CE (pág. 54), la Comunicación de la Comisión relativa a las orientaciones informales sobre cuestiones nuevas relacionadas con los artículos 81 y 82 del Tratado CE que surjan en asuntos concretos (cartas de orientación) (pág. 78), la Comunicación de la Comisión sobre la tramitación de denuncias por parte de la Comisión al amparo de los artículos 81 y 82 del Tratado CE (pág. 65), las Directrices relativas al concepto de efecto sobre el comercio contenido en los artículos 81 y 82 del Tratado (pág. 81) y las Directrices relativas a la aplicación del apartado 3 del artículo 81 del Tratado (Pág. 97).

CEE Reglamento 773/2004, relativo al desarrollo de los procedimientos de la Comisión con arreglo a los artículos 81 y 82 del Tratado CE, de 7 de abril de 2004, Diario Oficial de la UE, DOUE L123/18 de 7 de abril de 2004.

CEE Reglamento n. ${ }^{\circ}$ 1/2003, de 16 de Diciembre de 2002, relativo a la aplicación de las normas sobre competencia previstas en los artículos 81 y 82 del TCE, Diario Oficial de la UE, DOCE L 001 de 4 de Enero de 2003.

CEE Reglamento n. ${ }^{\circ}$ 17/1962, de 21 de Febrero de 1962, Primer Reglamento de aplicación de los artículos 85 y 86 del Tratado, Diario Oficial de la UE, DOCE 204/62.

CEE Tratado de Funcionamiento de la Unión Europea, Diario oficial de la UE, DOUE C 111/47 de 9 de mayo de 2008.

CEE Versión consolidada del Tratado de la Unión Europea, Diario oficial de la UE, DOUE C 321 E/1de 29 de diciembre de 2006.

Cengiz, F. (2010). Multi-Level Governance in competition Policy: The European Competition Network, European Law Review, 35, pp. 606-667.

Concepción Rodríguez, J., Gimeno-Bayón Cobos, R. E Rodríguez Vega, L. (2004). Coordinación entre los tribunales, la Comisión y las autoridades nacionales en la aplicación de los arts. 81 y 82 del TCE, Cuadernos de derecho Judicial, (17), pp. 191-218.

Creus Carreras, A., E Amador Peñate, O. (2005). Procedimiento administrativo ante la Comisión Europea y control jurisdiccional del TJCE. En J.M. Beneyto Pérez-Cerdá \& J. Maillo Gonzalez Orús (direct.), Tratado de derecho de la competencia. Unión Europea y España, Madrid: Bosch.

Dabbah, M. (2010). International and comparative competition law. Nueva York: Cambridge University Press.

Daly, A. (2011). The Legality of deep packet inspection. International Journal of Communications Law \& Policy. (14), pp. 1-12.

Daujotas, R. (2011). Extraterritorial Application of Competition Law: different angles - Same Conclusion, Documento de trabajo. pp. 1-29. 
Dekeyser, K., E Dalheimer, D. (2005). Cooperation within the European Competition Network - Taking stock after 10 months of case practice. En Lowe, P. E Reynolds, M. (eds.), Antitrust Reform in Europe: a year in practice, International Bar Association. Londres, pp. 105-123.

Dekeyser, K., E De Smijter, E. (2005). The Exchange of evidence within the ECN and how it contributes to the European co-operation and co-ordination in cartel cases, Legal Issues of Economic Integration, (32), pp. 161-174.

Dekeyser, K., E Jaspers, M. (2007). A New Era of ECN Cooperation, World Competition: Law and Economics Review, 30(3), pp. 3-24.

Fitzgerald, V. (2002). Cooperación Tributaria Internacional y Movilidad de Capital, Revista de la Cepal, (77), pp. 67-81.

Flynt Blanck, P. (2002). Tratado de Defensa de la Libre competencia. Lima: Fondo Editorial. Pontificia Universidad Católica del Perú.

Furse, M. (2006). Competition Law of the EC and UK, Nueva York: Oxford University Press.

Gauer, C. (2005). Due Process in the face of divergent National Procedures and sanctions, paper presentado en la conferencia Antitrust Reform in Europe: A year in practice papers, International Bar Association, Bruselas, 9 al 11 de Marzo de 2005, pp. 1-18.

Geradin, D., Reysen, M., E Henry, D. (2008). Extraterritoriality, Comity and cooperation in the EC Competition Law, Documento de trabajo. pp. 1-18.

Gerard, D. (2013). The ECN - Network antitrust enforcement in the European Union. En Lianos, I. E Géradin, D. (Eds.) Handbook on European Competition Law, 181-216), Londres: Edward Elgar.

Guillén Camarés, J. (2013). La cooperación entre jueces y autoridades administrativas en la aplicación privada del derecho de la competencia. En Font Ribas, A. E Gómez Trinidad, S. (coord.). Competencia y acciones de indemnización: actas del Congreso Internacional sobre daños derivados de ilícitos concurrenciales. Madrid: Marcial Pons.

Holmes, M., E Lennon, P. (2004). Causation-The Route to Damages, European Competition Law Review, 25(8), pp. 475-478.

Hovenkamp, H. (2003). The Rationalization of Antitrust, Harvard Law Review, 116(3), pp. 917-945.

Idot, L. (2004). A necessary step towards common procedural standarts of implementation for articles 81 \& 82 EC without the Network. En Ehlermann, C. D. E Atanasiu, I. (Eds.). European Competition Law Annual 2002: Constructing the EU Network of Competition Authorities.Oxford: Hart Publishing.

Inglaterra. Enterprise Act 2002, de 7 de Noviembre de 2002. 
Jones, C. (2003). A New Dawn for Private Competition Law Remedies in Europe?

Reflections from the U.S. En Ehlermann C.D. \& Atanasiu, I. (Eds.). European Competition Law Annual 2001: Effective private enforcement of EC Antitrust Law. Oxford: Hart Publishing.

Kekelekis, M. (2009). The European Competition Network (ECN): It Does Actually Work Well, Eipascope, (1), pp. 35-39.

Komninos, A. (2007a). Effect of Commission Decisions on private antitrust litigation: Setting the story straight, Common Market Law Review, 44(5), pp. 1387-1428.

Komninos, A. (2007b). Modernisation and Descentralisation: Retrospective and Prospective. En Ehlermann, C. D. \&. Amato G (Eds.). EC Competition Law. A Critical Assessment. Oxford: Hart Publishing.

Korah, V. (2007). An introductory guide to EC Law and practice, Oxford \& Portland: Hart Publishing.

Lande, R. (2004). Five Myths about antitrust damages, University of San Francisco Law Review, 40, pp. 651-675.

Mackenrodt, M. (2008). Private Incentive, Optimal Deterrence and Damage Claims under Article $82 \mathrm{EC}$. The Interaction between the Economic Review of the Prohibition of Abuses of Dominant Positions and Private enforcement. En Mackenrodt, M.C., Conde Gallego, B. \& Enchelmaier, S. (Eds.) Abuse Of dominant position: New interpretation, new enforcement, new mechanisms? Munich: Springer. Massey, P. (2002). Reform of EC competition law: substance, procedure and institutions. En Hawk, B. E. (Eds.). Reform of EU competition law. Nueva York: Juris Publications.

Mataija, M., (2010). The European competition Network and the Shaping of EU competition policy, Croatian Yearbook of European Law and Policy, 6, 75-101.

Nazzini, R., \& Andenas, M. (2006). Awarding damages for breach of competition law in English courts-Crehan in the court of appeal, European Business Law Review, 17(4), pp. 1191-1210.

Nazzini, R. (2004). Concurrent proceedings in Competition Law procedure, evidence and remedies. Oxford, Nueva York: Oxford University Press.

Ortiz Baquero, I. (2001). La aplicación privada del derecho de la competencia. Los efectos civiles derivados de la infracción de las normas de libre competencia, Madrid: La ley, Wolters Kluwer.

Pace, L. (2007). European Antitrust Law. Prohibitions, Merger Control and Procedures, Edward Elgar Publishing, Cheltenham.

Parada Vásquez, R. (2005). El sistema garantizador del derecho de defensa de la competencia. En Garrido Espá, L. (dir.). La defensa de la competencia por los 
Órganos Judiciales. El Reglamento CE 1/2003. Madrid: Consejo General del Poder Judicial.

Pastor, J. (2005). La política comunitaria de la competencia, Economía de la Unión Europea Thomson Civitas, Navarra.

Paulis, E. (2001). Coherent Application of EC competition rules in a system of parallel competences. En Ehlermann, C.D. E Atanasiu, I. (Eds.). European Competition Law Annual 2000: the modernisation of EC antitrust policy Oxford: Hart Publishing.

Poehls Bustos, E. (2013). Instrucción de carácter general No. 2 dictada por el tribunal de Defensa de la libre competencia, Revista chilena de derecho, 40(3), pp. 1027-1033.

Polster, S. (2008). Access to cartel evidence as a key to enhanced private enforcement: The Austrian example, Chambers client report, (25).

Reichelt, D. (2005). To what extent does the co-operation within the European Competition network protect the Rights of undertakings? Common Market Law Review, (3), pp. 745-782.

Schaub, A. (octubre de 2001). Continued focus on reform - Recent developments in EC competition policy, discurso presentado en Fordham Corporate Law Institute - Twenty-eighth Annual Conference On International Antitrust Law and Policy, New York, EE.UU

Soto Pineda, J. (2010). Aproximación a la implementación de los programas de clemencia como instrumentos del derecho de la competencia, ConTextos, (3), pp. 153-172.

Soto Pineda, J. (2012). Vías de aplicación del derecho de la competencia. Madrid: Universidad Autónoma de Madrid.

Soto Pineda, J. (2013a). A propósito de un elemento esencial de la defensa de la competencia en Europa: las facultades de investigación de la Comisión en materia de inspección, Revista de Ciencias jurídicas y sociales, 16(1), pp. 165-212.

Soto Pineda, J. (2013b). La doctrina y la evaluación de tendencias en la aplicación de la normativa "antitrust", Revista de derecho Mercantil, (288), pp. 223-267.

Soto Pineda, J. (2014). Public enforcement y descentralización en la aplicación de las normas de libre competencia en la Comunidad Europea y en España. Bogotá: Universidad Externado de Colombia.

Temple Lang, J. (2000). Decentralised Application of Community Competition Law. En J. Rivas y M. Horspool (Eds.). Modernisation and Decentralisation of EC Competition Law. La Haya: Kluwer Law International. 
Tierno Centella, M., E Peña Castellot, M. (2002). La comunicación sobre la dispensa del pago de las multas y la reducción de su importe en caso de cártel, Gaceta Jurídica, (220), pp. 101-111.

Tosato, G.L., \& Bellodi, L. (2006). EU Competition Law, Leuven: Editorial Claeys $\mathcal{G}$ Casteels.

Unctad. (2013). Conferencia de las Naciones Unidas sobre comercio y desarrollo, Modalidades y procedimientos de cooperación internacional en los asuntos de competencia que afectan a más de un país, Ginebra, pp. 1-21.

Unión Europea. Comisión Europea (2003). "XXXII Informe sobre la política de competencia", prólogo de Mario Monti. Bruselas.

Unión Europea. (2010). European Competition Network, ECN Brief, special Issue. A look inside the ECN: Its members and its work. pp. 1-44.

Unión Europea, Sala quinta. (19 de Mayo de 1994) Sentencia del Tribunal de Justicia de la Unión Europea, asuntos C-36/92 P, Samenwerkende ElektriciteitsProduktiebedrijuen NV (SEP) Vs. La Comisión de la Unión Europea.

Unión Europea, Sala quinta. (24 de junio de 1986) Sentencia del Tribunal de Justicia de la Unión Europea, asunto 53/85, AKZO Chemie BV Vs. La Comisión de la Unión Europea.

Unión Europea. (13 de Febrero de 1979). Sentencia del Tribunal de Justicia de la Unión Europea, Hoffmann-La Roche \& Co. AG Vs. La Comisión de la Unión Europea, asunto 85/76.

Unión Europea. (16 de Julio de 1992). Sentencia del Tribunal de Justicia de la Unión Europea, Asociación Española de Banca, asunto C-67/9.

Unión Europea. (17 de Octubre de 1989). Sentencia del Tribunal de Justicia de la Unión Europea, Dow Benelux NV Vs. La Comisión de la Unión Europea, asunto 85/87.

Unión Europea. (18 de septiembre de 1992). Sentencia del Tribunal de Justicia de la Unión Europea, Automec Srl Vs. La Comisión de la Unión Europea, asunto T24/90.

Unión Europea. (21 de septiembre de 1989). Sentencia del Tribunal de Justicia de la Unión Europea, de, Hoechst A. G. Vs. La Comisión de la Unión Europea, asuntos acumulados $46 / 87$ y $227 / 88$.

Unión Europea. (22 de octubre de 2002). Sentencia del Tribunal de Justicia de la Unión Europea, de, Roquette Frères SA Vs. Directeur géneral de la concurrencede la consommation et de la répression des fraudes, y la Comisión de la Unión Europea, asunto C-94/2000.

Unión Europea. (25 de Enero de 2007). Sentencia del Tribunal de Justicia de la Unión Europea, Dalmine SpA Vs. La Comisión de la Unión Europea, asunto C-407/04 P. 
Unión Europea, Sala primera ampliada. (20 de Febrero de 2001) Sentencia del Tribunal de Primera Instancia, Mannesmannröhren-Werke AG Vs. La Comisión de la Unión Europea, asunto T-112/98.

Unión Europea. (20 de abril de 1999). Sentencia del Tribunal de Primera Instancia, de, Limburgse Vinyl Maatschappij NVy Otros Vs. La Comisión de la Unión Europea, asuntos acumulados T-305/94, T-306/94, T-307/94, T-313/94, T-314/94, T-315/94, T-316/94, 318/94, T-325/94, T-328/94, T-329/94 y T-335/94.

Unión Europea. (24 de Enero de 1995). Sentencia del Tribunal de Primera Instancia, Bureau européen des médias de l'industrie musicale (BEMIM) Vs. La Comisión de la Unión Europea, asunto T-114/92.

Unión Europea. (28 de Febrero de 1991). Sentencia del Tribunal de Justicia de la Unión Europea, Stergios Delimitis Vs. Henninger Bräu AG, asunto C-234 de 1989.

Unión Europea. (18 de Septiembre de 1992). Sentencia del Tribunal de Justicia de la Unión Europea, Automec Srl Vs. La Comisión de las Comunidades Europeas, asunto T-24/90.

Van Bael, I., \& Bellis, J. (2010). Competition Law of the European Community, Kluwer Law International, Alphen aan den Rijn.

Van Der Woude, M. (2004). Exchange of Information within the European Competition Network: Scope and Limits. En Ehlermann, C.D. \& Atanasiu, I. (Eds.), European Competition Law Annual 2002: Constructing the EU Network of Competition Authorities. Oxford: Hart Publishing.

Van Der Woude, M. (noviembre de 2003). The modernization paradox: Controlled descentralization, Trabajo presentado en seminario Europeanisation of National Systems en el International Bar Association 10 Annual advanced Competition Law Conference, Bruselas

Van Gerven, Y. (2006). Regulation 1/2003: Inspections ("Dawn Raids") and the rights of defence. En C. Baudenbacher (Eds.) Neueste Entwicklungen im europäischen und internationalen Kartellrecht, (pp. 327-3571). St. Galler International, Helbing Lichtenhahn Verlag, Basilea.

Velasco San Pedro, L., Alonso Ledesma, C., Herrero Suarez, C., Almunia, J., Arribas Hernández, A., Bayo Álvarez, R., \& Yanes Yanes, P. (2011). Private enforcement of competition law. Valladolid: Lex Nova.

Vez Pazos, A. (2009). ¿Aplicación privada o pública?, Mercados de La Voz de Galicia, 10 de Mayo de 2009, p. 2.

Vivanco Martínez, A. (2008). Transparencia de la función pública y acceso a la información de la administración del Estado: una normativa para Chile. Revista Chilena de derecho, 35(2), pp. 371-398. 
Whish, R. (2008) Competition Law, Londres: Oxford University Press.

Widegren, M. (2004). Consultation among Members within the Network. En Ehlermann, C.D. E Atanasiu, I. (Eds.), European Competition Law Annual 2002: Constructing the EU Network of Competition Authorities, (pp. 419-426) Oxford: Hart Publishing.

Wils, W. (2004). The EU Network of Competition Authorities, The European Convention on Human Rights and the Charter of Fundamental Rights of the EU. En C.D. Ehlermann E I. Atanasiu (Eds.). European Competition Law Annual 2002: Constructing the EU Network of Competition AuthoritiesOxford: Hart Publishing. Wils, W. (2002). The Optimal Enforcement of EC antitrust Law, La Haya: Kluwer Law International. 
